\title{
The influence of cut direction and process parameters in wire electrical discharge machining of carbon fibre-reinforced plastic composites
}

\author{
Ramy Abdallah ${ }^{1,2} \cdot$ Sein Leung Soo ${ }^{1}$ (D) Richard Hood $^{1}$ \\ Received: 8 August 2020 / Accepted: 13 January 2021 / Published online: 11 February 2021 \\ (C) The Author(s) 2021
}

\begin{abstract}
The paper details a comprehensive experimental investigation on the influence of operating parameters and cut direction (parallel and perpendicular to fibre orientation) when wire electrical discharge machining (WEDM) unidirectional CFRP composites using zinc-coated brass wire $(0.25-\mathrm{mm}$ diameter). A Taguchi L18 fractional factorial orthogonal array considering four variable parameters including open voltage, ignition current and pulse-on time as well as pulse-off time was carried out for each cut direction. Results showed that a $\sim 16 \%$ increase in maximum material removal rate was achieved when machining parallel to fibre direction $\left(2.41 \mathrm{~mm}^{3} / \mathrm{min}\right)$ compared to cutting perpendicular to the fibres $\left(\sim 2.08 \mathrm{~mm}^{3} / \mathrm{min}\right)$, which was attributed to the higher electrical conductivity of the workpiece along the fibre length leading to greater discharge energies. This however resulted in relatively larger average kerf widths and poorer workpiece surface roughness (Sa) caused by the Joule heating effect. Workpieces machined parallel to fibre direction were generally free of any major edge defects, in contrast to severe delamination observed on both the top and bottom surfaces of specimens cut perpendicular to fibre orientation. High-magnification scanning electron microscopy of the machined surfaces revealed the presence of adhered resin material, fibre cracking, cavities/gaps in the matrix phase and interlayer cracks on most of the samples analysed, with damage severity dependent on the operating parameters and cut direction.
\end{abstract}

Keywords Electrical discharge machining $\cdot$ Material removal rate $\cdot$ Kerf width $\cdot$ Surface roughness $\cdot$ Composites

\section{Introduction}

The superior characteristics of carbon fibre-reinforced plastic (CFRP) in terms of low density $\left(1.5-2 \mathrm{gm} / \mathrm{cm}^{3}\right)$ with high specific strength $(\sim 785 \mathrm{kN} \cdot \mathrm{m} / \mathrm{kg})$, high elastic modulus $(75$ $105 \%$ of steel), good wear/corrosion and fatigue resistance as well as outstanding damping attributes have led to its increasing use, particularly within the aerospace, automotive and sporting equipment industries [1-6]. Indeed, up to $50 \%$ of the weight in some the latest commercial passenger aircraft

Sein Leung Soo

s.1.soo@bham.ac.uk

1 Machining Research Group, Department of Mechanical Engineering, School of Engineering, University of Birmingham, Edgbaston, Birmingham, UK

2 Production Engineering Department, Faculty of Engineering, Helwan University, Helwan, Cairo, Egypt such as the Airbus A350XWB and Boeing 787 is comprised of CFRP, which has resulted in fuel savings and lower exhaust emissions [7]. Drilling of CFRP is considered one of the principal machining processes in the aerospace sector, which is used to produce bolt/rivet holes in order to facilitate joining of various sections in the assembly process [8-10]. This is exemplified by the substantial number of holes required in private jets and bomber/transport aircraft, which range between 250,000-400,000 and 1,000,000-2,000,000 holes respectively [11]. However, the machinability of CFRP is generally considered to be challenging, not least due to its inhomogeneous/anisotropic properties as well as the abrasive nature of the carbon fibre reinforcement. Thus, the machining of CFRP using conventional processes such as milling and drilling is typically characterised by high tool wear/short tool life leading to poor surface integrity, with defects such as delamination, fibre pull out, uncut fibres, splintering, matrix cracking and burn commonly occurring [12-15]. Therefore, research on investigating alternative machining technologies has been increasing in recent years to alleviate the limitations 
of conventional processes. The feasibility and performance of several non-conventional processes such as ultrasonic, abrasive waterjet and laser beam machining have been evaluated for cutting CFRP, with benefits including lower cutting forces, tool wear and reduced delamination observed [16-20]. Nonetheless, a number of drawbacks such as workpiece delamination and the presence of heat-affected zones (HAZ) particularly with laser machining remain [21].

Electrical discharge machining (EDM) is another nonconventional process that has been assessed where material is eroded by controlled electrical sparks generated between an electrode and the workpiece. Sheikh-Ahmed and Shinde [11] evaluated the influence of process parameters (primarily discharge current and pulse duration) on the machinability of CFRP (electrode wear, material removal rate, delamination, hole tapering as well as hole size deviation) during EDM drilling using copper and graphite electrodes. At a pulse-on time of $190 \mu \mathrm{s}$, the graphite electrode was found to achieve higher material removal rates (MRRs) at different current levels with a maximum value of $29.3 \mathrm{~mm}^{3} / \mathrm{min}$ observed at 2 A compared to copper $\left(21.3 \mathrm{~mm}^{3} / \mathrm{min}\right)$, but at the expense of greater electrode wear rates $\left(5 \mathrm{~mm}^{3} / \mathrm{min}\right.$ for graphite against $0.82 \mathrm{~mm}^{3} /$ min with copper). In addition, reduced levels of delamination (delamination factor of $\sim 1.15$ ) for both electrodes were observed at low current of $0.4 \mathrm{~A}$ with pulse duration varying from 20 to $105 \mu \mathrm{s}$. However, deviation in hole size was influenced by increasing current and pulse duration where graphite achieved the highest value of $\sim 4.5 \%$ at $2 \mathrm{~A}$ and $190 \mu$ s respectively. With regard to hole tapering, a low pulse-on time $(20 \mu \mathrm{s})$ led to a large taper of $\sim 0.044 \mathrm{~mm}$ at intermediate current of $1.2 \mathrm{~A}$ when employing copper electrodes, whilst the largest taper of $\sim 0.048 \mathrm{~mm}$ was observed when operating at high current of $2 \mathrm{~A}$ using graphite electrodes. In related work, Sheikh-Ahmed [21] studied the material removal mechanisms and resulting workpiece damage including HAZ, hole tapering and surface delamination in EDM drilling of CFRP with respect to varying current and pulse-on time. It was reported that epoxy matrix decomposition and fracture/ vaporisation of fibres due to thermal energy from the plasma as well as Joule heating caused by short-circuiting of the conductive fibres were the principal cutting mechanisms. In terms of delamination, this was found to be prominent at the hole entry location and was significantly influenced by discharge current, whereas changes in pulse-on time had a major effect on the resulting degree of HAZ and hole tapering. More recently, a comprehensive investigation by Yue et al. [22] revealed that in addition to plasma and Joule heating, mechanical- and chemical-based material removal mechanisms were also present during EDM of CFRP. Using a high-speed video camera together with a laser bandpass filter, high-velocity jets/streams of gaseous debris (composed of vaporised/sublimated epoxy matrix and carbon fibres) generated by the high temperatures during the discharge process were seen emanating from the plasma channel. The force of the gaseous jets were observed breaking and removing exposed fibres around the discharge zone, particularly when machining workpieces with fibres orientated in the horizontal direction (parallel to surface). Trials comparing the performance of deionised water against an oil-based dielectric showed significantly higher cutting speeds were achieved with the former (up to $\sim 0.6 \mathrm{mg} / \mathrm{min}$ vs. $\sim 0.2 \mathrm{mg} / \mathrm{min}$ ). This was attributed to the oxygen produced from dissociation of the deionised water during spark discharges, which increased the thermal energy generated and associated material removal rate.

Apart from drilling operations, EDM has also been evaluated as a method for removing uncut fibres (deburring) in mechanically drilled CFRP composites. Islam et al. [23] investigated the effect of capacitance on MRR for a range of electrode materials (copper, brass, aluminium and steel). The results indicated that the highest MRR $\left(\sim 6.3 \mathrm{~mm}^{2} / \mathrm{min}\right)$ was recorded when utilising copper electrodes due to its greater electrical conductivity $\left(58.5 \times 10^{6} \mathrm{~S} / \mathrm{m}\right)$ whilst the aluminium electrodes produced the lowest MRR $\left(\sim 3.7 \mathrm{~mm}^{2} / \mathrm{min}\right)$ at equivalent capacitance levels, but with no signs of workpiece delamination around the hole. The performance of dry EDM involving the use of oxygen and air as the dielectric medium was also tested for removing uncut fibres in CFRP and compared against results obtained when employing oil [24]. In general, increasing the capacitance, voltage and gas pressure as well as operating with positive tool polarity led to higher MRR. Furthermore, the MRR was approximately two- and threefold higher when using air and oxygen, respectively, compared to an oil dielectric. The feasibility of ultrasonicassisted EDM (UA-EDM) for deburring of CFRP was investigated with results compared against dry EDM using copper electrodes [25]. According to the analysis of variance (ANOVA), capacitance, pulse-on time and vibration amplitude had a significant influence on the MRR. The fibre removal rate in UA-EDM was higher compared to dry EDM by eliminating the gap between electrode and workpiece, which resulted in increasing spark density and vaporisation on workpiece material. However, machining performance deteriorated when pulse-on time exceeded $200 \mu$ s because of the fibre burrs generated by high discharge energy that filled small gap caused by high amplitude leading to reduction in the reference voltage and MRR. Likewise, with increasing vibration amplitude to $5.04 \mu \mathrm{m}$, the gap became quite small yielding ineffective/unstable spark generation. Kumar et al. [26] explored the effect of variation in voltage, electrode speed and capacitance during micro EDM drilling of CFRP using a $110-\mu \mathrm{m}$ diameter electrode, which achieved an aspect ratio of 10.9 (hole depth of $1.2 \mathrm{~mm}$ ). Both voltage and capacitance were found to be statistically significant factors with respect to maximising MRR and minimising electrode wear rate, whereas electrode speed had no major influence on either response. 
Conversely, published research concerning the wire EDM (WEDM) of CFRP is relatively scarce. Lau and Lee [27] detailed one of the earliest studies comparing the performance of WEDM and laser cutting of woven CFRP (2.5 mm thick) in terms of MRR, edge tapering and workpiece surface damage. Laser machining demonstrated significantly superior MRR $\left(\sim 95 \mathrm{~mm}^{2} / \mathrm{min}\right)$ compared to WEDM $\left(\sim 12 \mathrm{~mm}^{2} / \mathrm{min}\right)$, although the latter showed better edge quality together with lower surface damage and HAZ. Limited trials involving WEDM of thin CFRP laminates (2-mm thickness) were performed by Yue et al. [22] using brass wire, with cutting carried out parallel and perpendicular to the fibre direction. Machining parallel to the fibres resulted in $\sim 18 \%$ higher cutting speed due to the increased electrical and thermal conductivity of fibres in the axial compared to transverse orientation. Abdallah et al. [28] recently reported results from a preliminary study to investigate the feasibility of WEDM for cutting 8.4-mm-thick unidirectional (UD) CFRP plates using zinccoated brass wire fed parallel to the fibres. The variable parameters included open voltage, ignition current and pulse-on/ off time, with the effects on MRR, kerf widths and surface damage on the top and bottom surfaces of the workpieces assessed. In general, there was no visible damage along the edges of the machined kerfs in any of the tests although the kerf widths were generally inconsistent over the length of cut due to variation in the top nozzle standoff distances, which affected flushing efficiency. The associated ANOVA indicated that ignition current had a major influence on MRR and kerf width on the top surface, whilst pulse-off time was a significant factor affecting MRR.

In an effort to improve machining stability, Dutta et al. [29] investigated the WEDM of 1-mm-thick woven CFRP using a molybdenum wire electrode $(0.18$-mm diameter) and utilising a 2-mm-thick metallic layer as an assisting electrode in a stacked configuration with the CFRP to promote spark initiation. The machining time was evaluated over a 4-mm cut length by changing current (2, 4 and $6 \mathrm{~A})$, and pulse-on ( 30 , 40 and $50 \mu \mathrm{s})$ and pulse-off time $(15,25$ and $35 \mu \mathrm{s})$. It was observed that the assisting electrode enhanced sparking and the generation/propagation of heat into the CFRP workpiece leading to material removal. Results showed that machining time increased at higher pulse-on and pulse-off times when operating at 2 A current, whilst cut time was reduced by $41-$ $52 \%$ when current was increased to $6 \mathrm{~A}$ (depending on pulseoff time). Similarly, Wu et al. [30] proposed a preheatingassisted WEDM (PAWEDM) technique for machining UDCFRP by sandwiching the composite workpiece between carbon steel plates, which acted as assisting layers. An analytical thermal model was used to show that the intense spark discharges occurring at the metallic layers resulted in greater transfer of heat generated to the section of wire interacting with the CFRP, which was sufficient to melt the low conductivity resin matrix of the composite workpiece. This significantly improved machining efficiency and prevented wire breakage, which was regularly observed in conventional WEDM of CFRP (without assisting layers) due to uncut epoxy resin material inducing stress concentrations in the wire. Experimental trials were performed at different cut directions to the fibre orientation $\left(0^{\circ}, 30^{\circ}, 45^{\circ}, 60^{\circ}\right.$ and $\left.90^{\circ}\right)$ to validate the theoretical model. Cutting with the PAWEDM configuration was successfully achieved over a distance of $10 \mathrm{~mm}$ for all cut directions, whilst improved kerf straightness and lower kerf widths were observed with increasing cut angle. Subsequent analysis of the machined surfaces however revealed typical damage characteristics including enlargement of fibre tips, fibre fusion and resin adhesion in addition to matrix loss and debonding. The present paper examines the influence of key operating process parameters as well as cutting direction with respect to fibre orientation on material removal rate, average kerf width, workpiece surface roughness and damage following WEDM of UD-CFRP composites.

\section{Experimental work}

\subsection{Workpiece material, machine tool and analysis equipment}

Square unidirectional CFRP plates with dimensions of $100 \times$ $100 \mathrm{~mm}$ and a thickness of $8.4 \mathrm{~mm}$ were used as the workpiece material. The plates consisted of 32 plies comprising intermediate modulus ( $294 \mathrm{GPa})$ carbon fibres preimpregnated within an epoxy resin matrix, which were manually laid up in the $0^{\circ}$ fibre direction followed by autoclave curing to consolidate the laminates. Table 1 details the main mechanical and physical characteristics of the carbon fibres. The experimental machining trials were performed on an AgieCharmilles Robofil FI240CC WEDM unit incorporating a CleanCut minimum damage generator; see Fig. 1a and the corresponding test setup in Fig. 1b. Workpieces were submerged in deionised water dielectric (conductivity of $\sim 5$ $\mu \mathrm{S} / \mathrm{cm}$ ) during machining whilst the electrode was a 0.25 -

Table 1 Mechanical and physical properties of carbon fibre

\begin{tabular}{ll}
\hline Parameter & Value \\
\hline Fibre diameter & $5 \mu \mathrm{m}$ \\
Tensile modulus & $294 \mathrm{GPa}$ \\
Tensile strength & $5880 \mathrm{MPa}$ \\
Fibre areal weight & $268 \mathrm{~g} / \mathrm{m}^{3}$ \\
Density & $1.8 \mathrm{~g} / \mathrm{cm}^{3}$ \\
Thermal conductivity & $70 \mathrm{~W} / \mathrm{m} \cdot \mathrm{K}$ \\
Electric resistivity & $1.3 \times 10^{-3} \Omega \cdot \mathrm{cm}$ \\
Strain & $2 \%$ \\
\hline
\end{tabular}



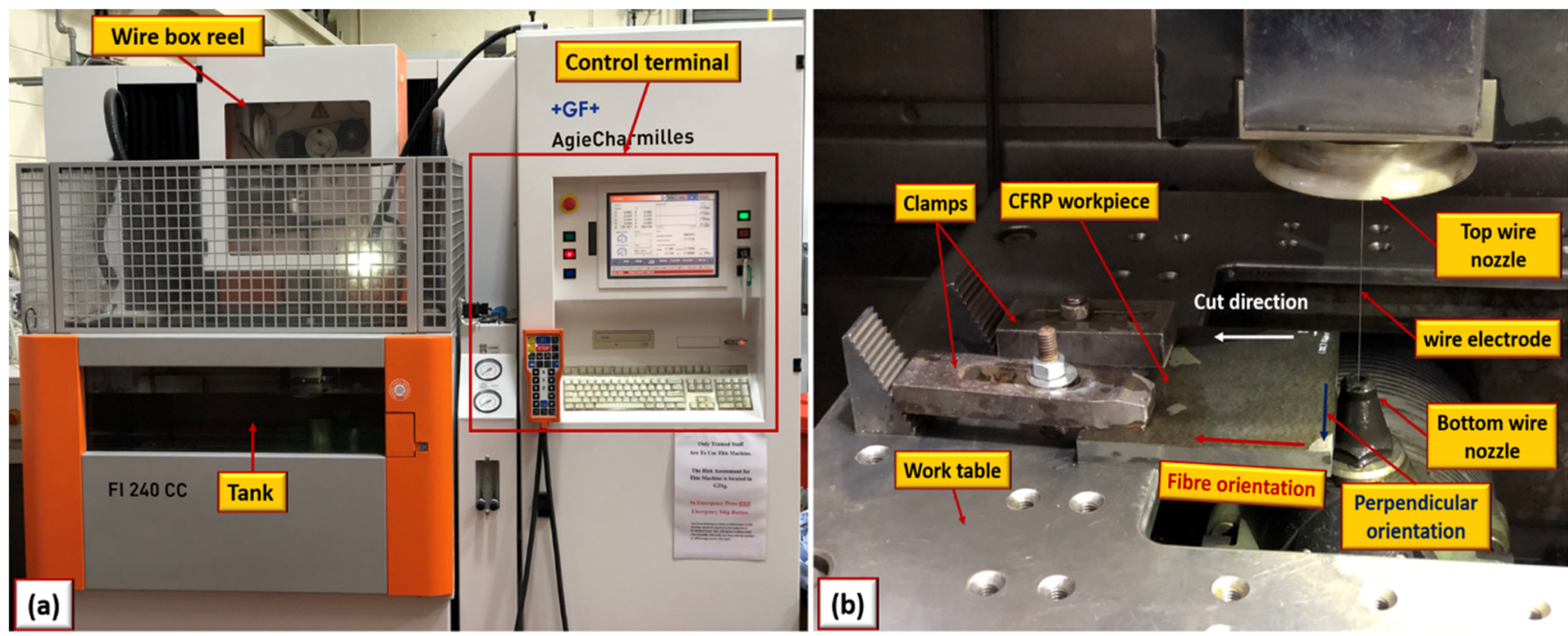

Fig. 1 a AgieCharmilles Robofil FI240CC machine and b experimental setup

$\mathrm{mm}$ diameter, high tensile strength $(800 \mathrm{MPa})$ brass core $\left(\mathrm{Cu}_{80} \mathrm{Zn}_{20}\right)$ wire coated with a double layer zinc-rich brass (commercial designation-Topas plus D). A schematic of the wire cross-section is shown in Fig. 2a. The wire was selected due to its relatively high strength, which was expected to provide superior straightness as well as increased resistance to wire breakage and hence improved process stability during machining.

The machined kerf width and 3D topographical plots to estimate surface roughness parameters involving $\mathrm{Ra}$ and $\mathrm{Sa}$ were evaluated using an Alicona G5 InfiniteFocus microscope, primarily at magnifications of $\times 5$ and $\times 20$ respectively. The mass of the workpiece samples before and after each experimental trial was weighed using a digital scale with a measuring range of 0.5 to $3500 \mathrm{~g}$ (precision of $0.01 \mathrm{~g}$ ). Micrographs of kerfs on the top and bottom faces of the workpiece were captured by a digital camera attached to a toolmakers microscope whilst high-resolution images of the machined surfaces were obtained with a JEOL JCM-6000 Plus benchtop scanning electron microscope (SEM).

\subsection{Experimental design and test procedures}

A fractional factorial Taguchi L18 experimental design was employed with variable factors and corresponding values selected based on results from preliminary exploratory trials, which included open gap voltage at 2 levels together with ignition current and pulse-on and pulse-off times each at 3 levels; see Table 2. Servo voltage, wire tension, wire speed, flushing pressure and discharge frequency were kept constant as detailed in Table 3 .

Table 4 shows the L1 8 orthogonal array employed for the 2 sets of experiments performed, one for cutting parallel and the other perpendicular to workpiece fibre orientation (see schematic in Fig. 2b), giving a total of 36 runs. Each test involved cutting a slot with a length of $12 \mathrm{~mm}$ and the machining time was recorded using a stopwatch. The MRR was subsequently calculated according to Eq.1 [31, 32]:

$\operatorname{MRR}=\frac{m_{\mathrm{b}-} m_{\mathrm{a}}}{\rho \times t_{\mathrm{m}}}$

where $m_{\mathrm{b}}$ and $m_{\mathrm{a}}$ are the masses of the specimens before and

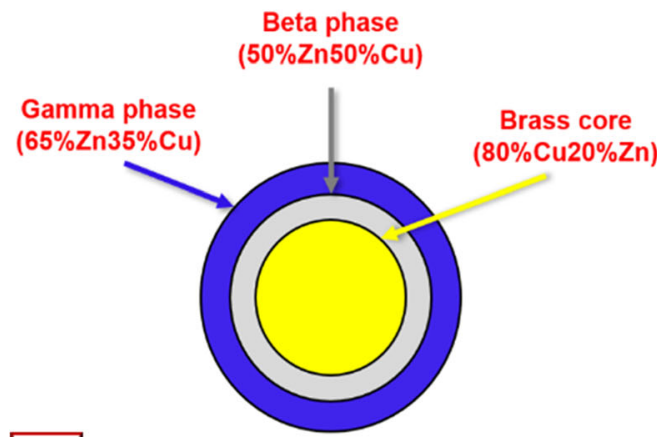

(a)

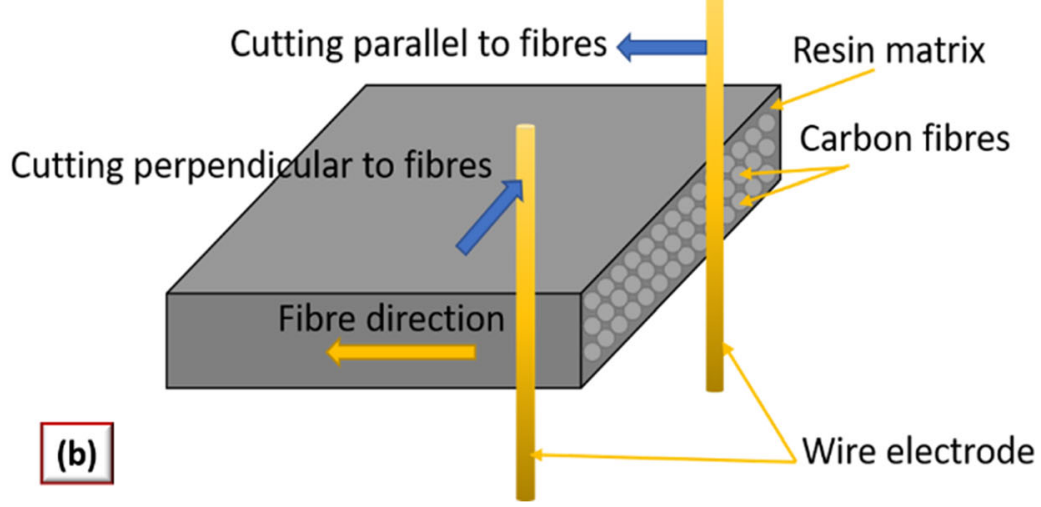

Fig. 2 Schematic representation of a Topas plus D wire composition and $\mathbf{b}$ cutting parallel and perpendicular to fibre orientation 
Table 2 Variable machining parameters

\begin{tabular}{llll}
\hline Machining parameter & Level 1 & Level 2 & Level 3 \\
\hline Open gap voltage, $\mathrm{V}_{\mathrm{o}}(\mathrm{V})$ & 120 & 140 & - \\
Ignition current, IAL $(\mathrm{A})$ & 3 & 4 & 5 \\
On time, A $(\mu \mathrm{s})$ & 0.8 & 0.9 & 1.0 \\
Off time, B $(\mu \mathrm{s})$ & 4 & 6 & 8 \\
\hline
\end{tabular}

after machining respectively $(\mathrm{g}), \rho$ is the specimen density $\left(\mathrm{g} / \mathrm{mm}^{3}\right)$ and $t_{\mathrm{m}}$ is the machining time ( $\left.\mathrm{min}\right)$.

The delamination factor $(F d)$ of the machined kerf edges on both the top and bottom workpiece surfaces was evaluated using Eq. 2 [33]:

$F d=\frac{W \max }{W}$

where $W_{\max }$ is the maximum delamination width of the machined kerf and $W$ is the average kerf width.

The average kerf width for each test was estimated from the mean of 18 measurements taken on the top and bottom of the workpiece ( 9 for each surface), which were recorded at approximately equal distances along the machined length. Both $2 \mathrm{D}$ and $3 \mathrm{D}$ roughness parameters ( $\mathrm{Ra}$ and $\mathrm{Sa}$ ) were determined by averaging measurements at three different zones (each over an area of $13.2 \mathrm{~mm}^{2}$ ) on the machined surface. For 2D parameters ( $\mathrm{Ra}$ ), 6 line measurements were recorded per zone (parallel and orthogonal to cutting direction). The cut off lengths were $0.8 \mathrm{~mm}$ and $887 \mu \mathrm{m}$ for $\mathrm{Ra}$ and $\mathrm{Sa}$ respectively.

Analysis of variance (ANOVA) was conducted to identify statistically significant factors (at $95 \%$ confidence interval) with respect to the measured responses. Parameter optimisation was conducted according to signal-to-noise $(\mathrm{S} / \mathrm{N})$ ratio analysis, with the objectives for maximising material removal rate whilst minimising kerf width and surface roughness. The highest $\mathrm{S} / \mathrm{N}$ ratio values indicated the optimal levels regardless of the target response. Confirmation tests were subsequently carried out based on the optimal parameter combination to validate each response, with corresponding $\mathrm{S} / \mathrm{N}$ ratio and mean values compared with those predicted by Eq. 3 [34]:

Table 3 Fixed machining parameters

\begin{tabular}{ll}
\hline Machining parameter & Level \\
\hline Servo voltage, Aj (V) & 15 \\
Wire tension, WB, (N) & 13 \\
Wire speed, WS, (mm/s) & 10 \\
Flushing pressure, INJ, (bar) & 16 \\
Frequency, FF (\%) & 10 \\
\hline
\end{tabular}

Table 4 L18 orthogonal array for both cutting directions

\begin{tabular}{|c|c|c|c|c|}
\hline Test no. & $\begin{array}{l}\text { Open voltage, } \\
\mathrm{V}_{\mathrm{o}} \\
(\mathrm{V})\end{array}$ & $\begin{array}{l}\text { Ignition } \\
\text { current, IAL } \\
\text { (A) }\end{array}$ & $\begin{array}{l}\text { Pulse-on t } \\
\text { ime, A } \\
(\mu s)\end{array}$ & $\begin{array}{l}\text { Pulse-off time, B } \\
(\mu \mathrm{s})\end{array}$ \\
\hline 1 & 120 & 3 & 0.8 & 4 \\
\hline 2 & 120 & 3 & 0.9 & 6 \\
\hline 3 & 120 & 3 & 1.0 & 8 \\
\hline 4 & 120 & 4 & 0.8 & 4 \\
\hline 5 & 120 & 4 & 0.9 & 6 \\
\hline 6 & 120 & 4 & 1.0 & 8 \\
\hline 7 & 120 & 5 & 0.8 & 6 \\
\hline 8 & 120 & 5 & 0.9 & 8 \\
\hline 9 & 120 & 5 & 1.0 & 4 \\
\hline 10 & 140 & 3 & 0.8 & 8 \\
\hline 11 & 140 & 3 & 0.9 & 4 \\
\hline 12 & 140 & 3 & 1.0 & 6 \\
\hline 13 & 140 & 4 & 0.8 & 6 \\
\hline 14 & 140 & 4 & 0.9 & 8 \\
\hline 15 & 140 & 4 & 1.0 & 4 \\
\hline 16 & 140 & 5 & 0.8 & 8 \\
\hline 17 & 140 & 5 & 0.9 & 4 \\
\hline 18 & 140 & 5 & 1.0 & 6 \\
\hline
\end{tabular}

$\widehat{\eta}=\bar{\eta}_{m}+\sum_{i=1}^{n_{o}}\left(\bar{\eta}_{i}-\bar{\eta}_{m}\right)$

where $\widehat{\eta}$ is the predicted value; $\bar{\eta}_{m}$ is the overall mean; $\bar{\eta}_{i}$ is the optimal level mean value.

\section{Results and discussion}

\subsection{Material removal rate and surface damage}

All of the tests achieved the 12-mm cut length criterion with machining duration ranging from 13.3 to 49.1 and 16.5 to $40.95 \mathrm{~min}$ for experiments undertaken parallel and perpendicular to the fibre direction respectively. Figure 3 shows comparative MRR results obtained for each test condition. The highest MRR of $2.41 \mathrm{~mm}^{3} / \mathrm{min}$ was obtained in test 9 when cutting parallel to the fibre direction, compared to a maximum of $1.94 \mathrm{~mm}^{3} / \mathrm{min}$ for tests performed orthogonal to the fibres. The former was primarily attributed to the higher electrical conductivity of the workpiece when cutting along the axial direction of fibres $(\sim 11.91 \mathrm{~S} / \mathrm{cm})$ as opposed to the transverse direction $\left(14.09 \times 10^{-2} \mathrm{~S} / \mathrm{cm}\right)$. Furthermore, parameter levels in test 9 involved a combination of the highest ignition current and pulse-on time coupled with the lowest pulse-off time, which generated increased discharge energies leading into resin evaporation. In addition to melting and vaporisation 
Fig. 3 Material removal rate for each test when machining parallel and perpendicular to fibre orientation $\checkmark$ Parallel to fibre $⿴$ Perpendicular to fibre

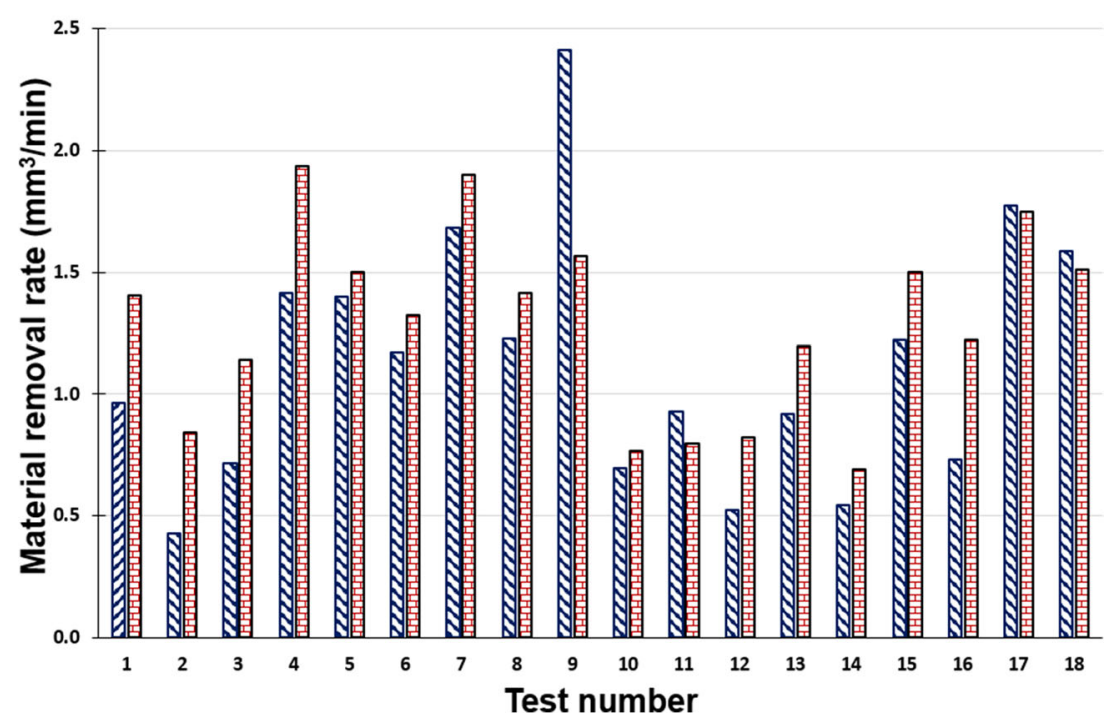

from spark discharges, material removal in tests performed parallel to fibre direction was also due to Joule heating caused by contact between the wire electrode and frayed fibres following resin evaporation, as illustrated by the schematic in Fig. 4. However, despite the lower conductivity, the MRR when cutting perpendicular to the fibres was generally higher than the corresponding trials performed parallel to fibre orientation for a large majority of test conditions; see Fig. 3. This was partly due to the larger nozzle standoff distance employed in the latter, which led to lower flushing efficiency and poor evacuation of fibre debris/decomposed matrix from the gap, thereby causing unstable sparking conditions in some of the tests. According to the ANOVA, ignition current and pulseoff time were found to be significant at the $5 \%$ level for MRR regardless of cut direction; see Tables 5 and 6 for results from trials undertaken parallel and perpendicular to fibre direction respectively. The corresponding percentage contribution ratio (PCR) was higher for ignition current at 43.28\%/48.47\% (perpendicular/parallel to fibre direction), as opposed to $18.56 \% /$ $24.27 \%$ for pulse-off time. In addition, voltage was also seen to have significant effect on MRR when cutting perpendicular to the fibres with a PCR of $16.56 \%$, whilst pulse-on time did not have a major influence irrespective of cut direction.

Figure 5 shows the main effects plot for MRR involving tests undertaken perpendicular to fibre orientation. Increasing ignition current generally led to higher MRR owing to greater discharge energies whilst a deterioration in MRR was observed at larger pulse-off times and voltage. The lower MRR with increasing pulse-off time was unsurprising, but the stronger spark intensity at the higher open voltage level was thought to have caused a greater flow of decomposed resin material in the spark gap, resulting in lower machining stability and efficiency. As reported previously, similar trends were observed for tests performed parallel to fibre direction [28]. Although not statistically significant, the influence of pulse-on time was somewhat unexpected, with higher MRR achieved at the lower pulse-on time level as shown in Fig. 5. This was potentially due to the presence of bent and fractured fibres caused by forces from the spark discharges and dielectric flushing/gaseous jets [22]. Following resin vaporisation, the uncut fibres become loose and are
Fig. 4 Schematic illustration of material removal mechanism when cutting parallel to fibre orientation

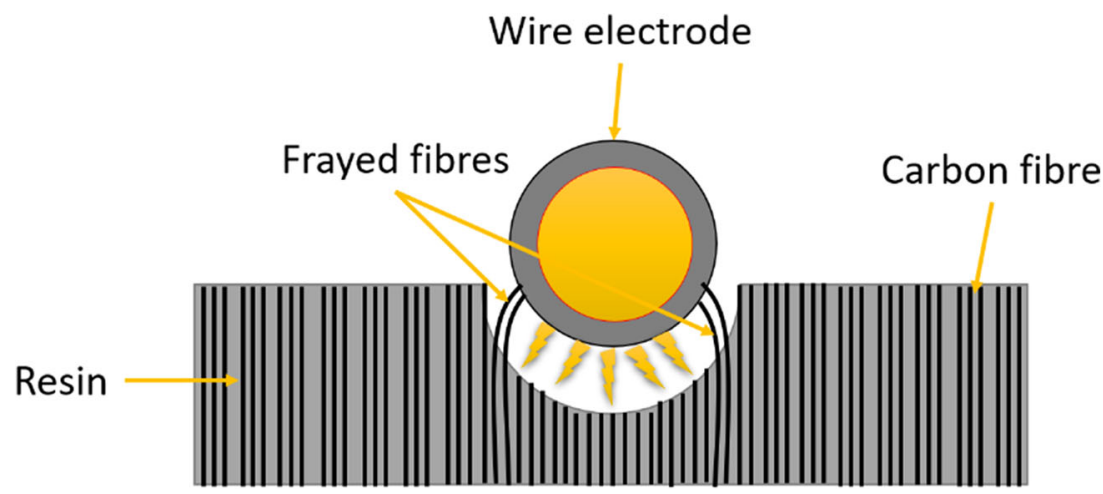


Table 5 Analysis of variance for MRR when machining parallel to fibre direction

\begin{tabular}{lllllll}
\hline Source & DF & Seq SS & Adj SS & Adj MS & $F$-value & $P$ value \\
\hline $\mathrm{V}_{\mathrm{o}}$ & 1 & 0.3452 & 0.3452 & 0.34524 & 4.78 & 0.054 \\
$\mathrm{IAL}$ & 2 & 2.2200 & 2.2200 & 1.11001 & 15.37 & $0.001^{*}$ \\
$\mathrm{~A}$ & 2 & 0.1814 & 0.1814 & 0.09071 & 1.26 & 0.326 \\
$\mathrm{~B}$ & 2 & 1.1116 & 1.1116 & 0.55582 & 7.70 & $0.009^{*}$ \\
Error & 10 & 0.7221 & 0.7221 & 0.07221 & & 24.27 \\
Total & 17 & 4.5804 & & & & 15.77 \\
\hline
\end{tabular}

*Significant at the $5 \%$ level

subsequently exposed to jetting force generated by high-speed gaseous jets as a result of evaporated gases from the workpiece material and collapse of the plasma channel. This material removal mechanism when machining perpendicular to the fibre orientation is illustrated by the schematic in Fig. 6. A longer pulse-on time would likely increase the amount of debris/ broken fibres in the spark gap, resulting in unstable machining and lower MRR.

Optical micrographs of the machined kerf/slot when cutting parallel to the fibres indicated that the workpiece was free of any serious surface damage such as delamination, matrix burn, uncut fibres or fibre pull out, even when operating at conditions resulting in the highest MRR (test 9), apart from a somewhat irregular edge profile. However, there were traces of bronze-coloured contaminants adhered on the bottom surface of the workpiece around the vicinity of the kerf, which was likely debris from the wire electrode as shown in Fig. 7(a). Conversely, severe delamination was evident along the edges of the kerf on both the top and bottom surfaces of the workpiece when machining perpendicular to the fibres' sides as shown in Fig. 7(b) from test 4 (highest MRR). The high temperatures in the plasma channel resulted in evaporation of the resin matrix, leaving loose carbon fibres that were exposed to impact forces from the spark discharges and associated gaseous jets in the machining gap. These forces likely caused fracture of the fibres due to their low bending strength leading to delamination. The corresponding delamination factor for the slot was determined based on the ratio of the maximum delamination width to the average kerf width, with a sample measurement shown in Fig. 7(c). It was found that the delamination factors measured on the top and bottom surfaces of the workpiece were similar with values of $\sim 1.97$ and $\sim 1.96$ respectively.

Figure 8 details SEM micrographs of machined surfaces from selected tests corresponding to the lowest, median and highest MRR together with the confirmation trial when cutting parallel to the fibres. The presence of adhered/resolidified resin, and broken fibre debris as well as severe/ near complete loss of matrix material due to decomposition/ vaporisation of the epoxy resin were observed on the machined surface from test 2 (lowest MRR of $0.43 \mathrm{~mm}^{3} / \mathrm{min}$ ), as shown in Fig. 8(a). Additionally, the ends of broken fibres appeared swollen possibly due to the accumulation and transfer of heat generated by the plasma in the discharge zone. At conditions leading to the median MRR $\left(1.13 \mathrm{~mm}^{3} / \mathrm{min}\right)$ in test 6 , the rise in discharge energy yielded greater deposition of resolidified material and matrix loss together with formation of pits/fractures at the fibre ends; see Fig. 8(b). The noticeable cavities in the adhered resin layer were possibly due to trapped gas and bubbles generated during collapse of the plasma channel. Figure 8(c) shows the surface obtained from test 9 representing the highest MRR $\left(2.41 \mathrm{~mm}^{3} / \mathrm{min}\right)$ achieved in the experiment. Here, considerably greater amounts of resolidified resin with wider cavities combined with loose/

Table 6 Analysis of variance for MRR when machining perpendicular to fibre direction

\begin{tabular}{|c|c|c|c|c|c|c|c|}
\hline Source & $\mathrm{DF}$ & Seq SS & Adj SS & Adj MS & $F$-value & $P$ value & PCR $(\%)$ \\
\hline $\mathrm{V}_{\mathrm{o}}$ & 1 & 0.4284 & 0.4284 & 0.42835 & 11.15 & $0.008 *$ & 16.56 \\
\hline IAL & 2 & 1.1195 & 1.1195 & 0.55976 & 14.57 & $0.001 *$ & 43.28 \\
\hline A & 2 & 0.1746 & 0.1746 & 0.08729 & 2.27 & 0.154 & 6.75 \\
\hline B & 2 & 0.4801 & 0.4801 & 0.24006 & 6.25 & $0.017 *$ & 18.56 \\
\hline Error & 10 & 0.3843 & 0.3843 & 0.03843 & & & 14.86 \\
\hline Total & 17 & 2.5869 & & & & & 100.00 \\
\hline
\end{tabular}

*Significant at the $5 \%$ level 
Fig. 5 Main effects plot for MRR when cutting perpendicular to fibre orientation

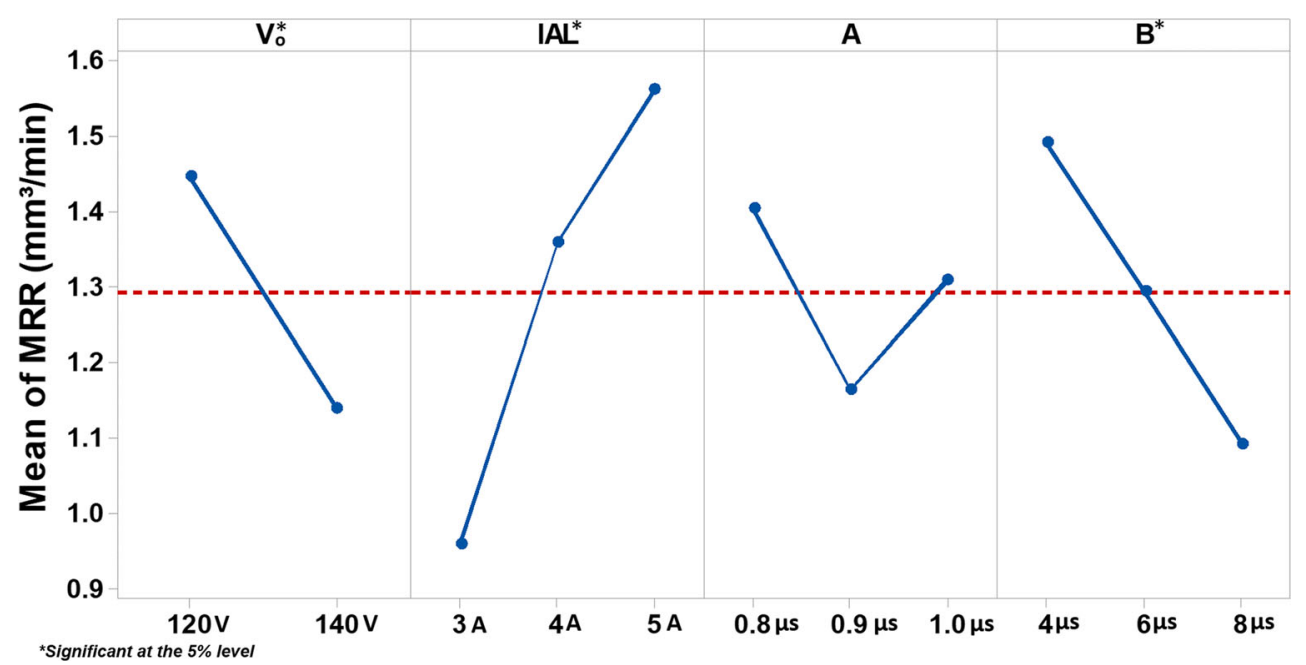

broken fibre fragments were apparent compared to surfaces seen in the other tests. This was probably due to the higher levels of epoxy decomposition coupled with the flow of deionised water or gaseous jets impinging on the exposed fibres, which were unable to withstand the bending stresses.

When cutting perpendicular to the fibre direction, a large proportion of the matrix material appeared to remain on the machined surface, albeit with some cavities observed as a result of resin/fibre loss; see Fig. 9. This was in stark contrast to the surfaces generated when machining parallel to the fibres as seen previously in Fig. 8. In test 14 showing the lowest MRR $\left(0.69 \mathrm{~mm}^{3} / \mathrm{min}\right)$, the cavities were generated due to decomposition of the epoxy matrix, which occurred at a temperature of $400{ }^{\circ} \mathrm{C}$ [21]. This was primarily seen at the interface regions between plies but also within individual prepregs layers, some of which were filled by re-solidified epoxy material. Additionally, the interlayer cracks between fibres displaying hexagonal cross sections were likely caused by swelling/expansion of the fibre ends due to the elevated temperatures generated during sparking, which compressed the fibres together as reported by Sheikh-Ahmed [21]. The machined surface topography produced in test 6 corresponding to the median MRR level $\left(1.29 \mathrm{~mm}^{3} / \mathrm{min}\right)$ shown in Fig. 9(b) was characterised by a network of resin craters covering the fibre piles as well as broken fibres and voids. The hexagonal cross-section of the fibre ends was more evident here compared to test 14 due to the higher discharge energy causing greater temperatures and increased swelling of the fibres. Similar damage characteristics were evident on the workpiece from test 4 with the highest MRR (1.94 $\left.\mathrm{mm}^{3} / \mathrm{min}\right)$; see Fig. 9(c). Craters and voids were also visible on the layer of melted epoxy, possibly due to higher discharge energies and entrapped gases produced from resin decomposition and evaporation.

\subsection{Kerf width}

Figure 10 shows the variation in average kerf widths in each test when machining parallel and perpendicular to the fibre orientation. The values ranged between $\sim 260$ and $283 \mu \mathrm{m}$ when cutting along the fibre direction whilst a smaller variation of $\sim 268$ to $274 \mu \mathrm{m}$ was observed when cutting perpendicular to the fibres. The larger difference between the lower and upper average values of kerf width in the former $(\sim 23 \mu \mathrm{m})$ compared with the latter $(\sim 6 \mu \mathrm{m})$ was possibly due to the higher electrical conductivity of the fibres in the axial
Fig. 6 Schematic illustration of material removal mechanism when cutting perpendicular to fibre orientation

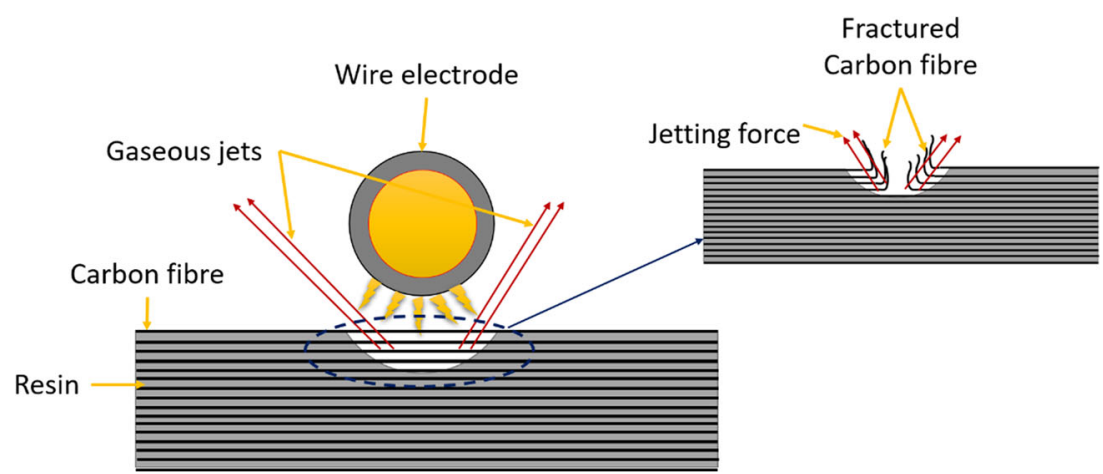


Fig. 7 Optical micrographs of the machined kerf in (a) test 9 when machining parallel to fibre direction, (b) test 4 (maximum MRR) when machining perpendicular to fibre direction and (c) delamination widths of the machined kerf at top surface when cutting perpendicular to fibre direction (a) Top surface

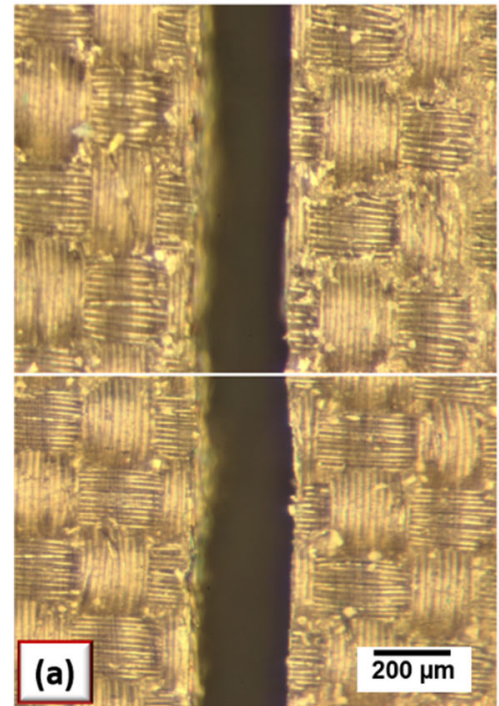

(a) Top surface

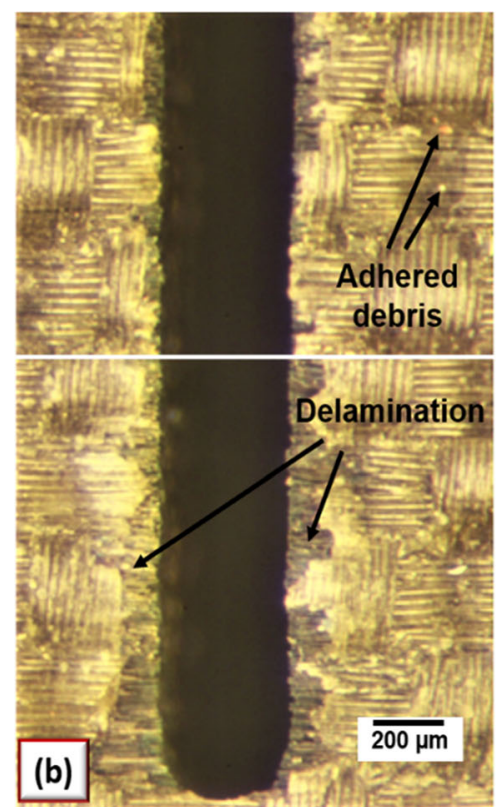

(b) Bottom surface

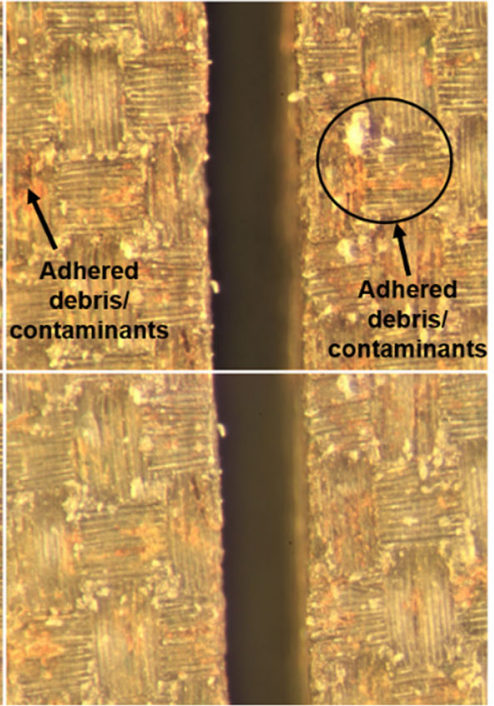

(b) Bottom surface
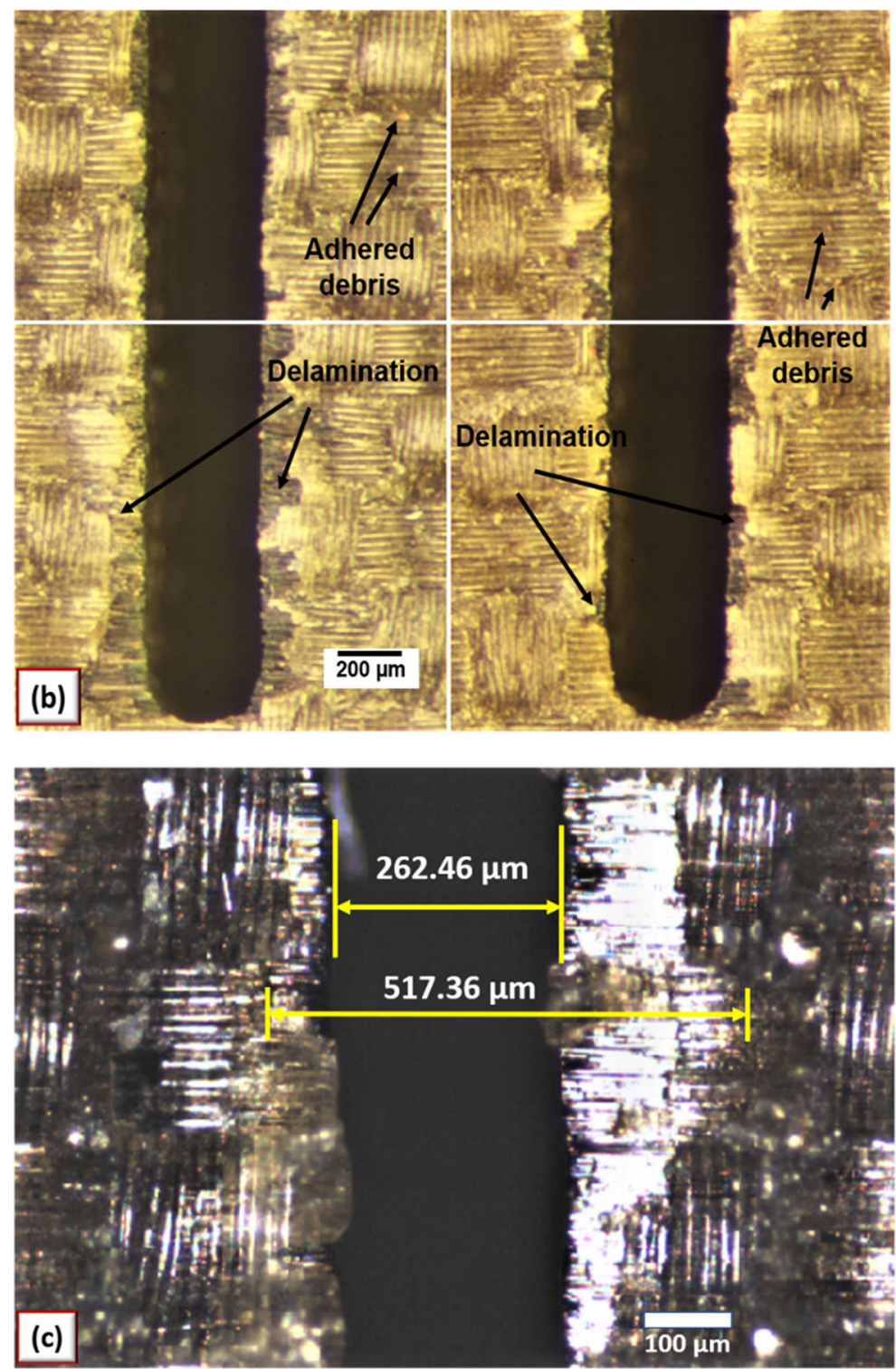
Fig. 8 SEM micrographs of machined surfaces when cutting parallel to fibre direction from (a) test 2-lowest MRR; (b) test 6 median MRR; and (c) test 9highest MRR
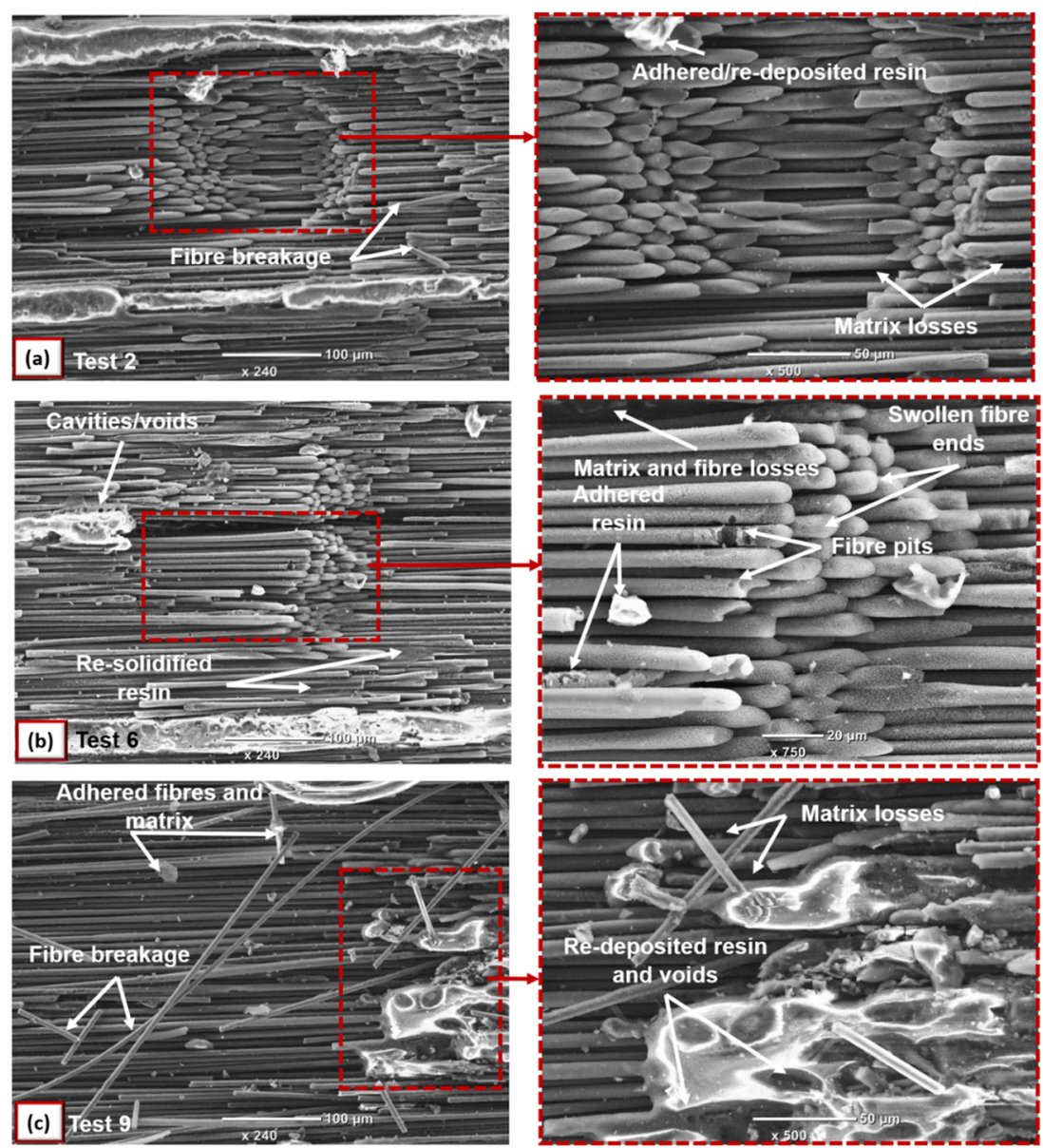

direction, leading to increased transfer of energy during sparking. However, results from the ANOVA indicated that none of the factors were statistically significant with respect to average kerf width for both cutting directions as shown in Tables 7 and 8 . The pulse-off time showed the highest percentage contribution ratio (PCR) with $17.49 \%$ followed by $10.6 \%$ for ignition current when cutting parallel to the fibres whilst pulse-on time achieved the highest PCR of $19.96 \%$ when machining perpendicular to fibre orientation. The relatively high residual error of $\sim 60 \%$ found in both cases suggests that other process parameters or interactions between the variables which have not been considered in the experimental design and analysis were possibly significant factors affecting the kerf width.

In general, wider kerfs were obtained when operating at the higher voltage of $140 \mathrm{~V}$, a trend illustrated by the main effects plot for average kerf widths shown in Fig. 11. This was attributed to the larger spark gap at elevated voltage whilst increasing pulse-on time also led to wider kerfs due to higher discharge energies. Conversely, increasing pulse-off time typically reduced kerf widths as a result of lower pulse frequency and intensity. In contrast, the influence of gap voltage on mean kerf width was marginal when cutting perpendicular to the fibres, as shown by the main effects plot in Fig. 12 .
Increasing pulse-off time reduced the kerf width as anticipated due to lower spark frequency as well as longer cooling time that dissipates more of the heat generated in the discharge gap. In contrast, the intermediate current level $(4 \mathrm{~A})$ resulted in smaller kerf widths due to faster cutting rates whilst the intermediate pulse-on time value $(0.9 \mu \mathrm{s})$ tended to increase kerf width from the longer interaction time between the spark and workpiece.

\subsection{Surface roughness}

The average linear (measured parallel and perpendicular to feed direction) and areal workpiece surface roughness measurements for each test when cutting parallel to the fibre direction are shown in Fig. 13. The lowest Ra values were observed along the feed direction (parallel to the fibre orientation) whilst the corresponding roughness perpendicular to the feed (measured across several individual plies) was higher by a factor of $\sim 1.5$ to 3 . The possible reason for this trend relates to the presence of gaps between fibre plies due to resin evaporation as well as re-solidified debris generated from epoxy decomposition adhering to the surface and spaces between fibres in the transverse direction. The $3 \mathrm{D}$ roughness $(\mathrm{Sa})$ levels were relatively similar to the average $\mathrm{Ra}$ values 
Fig. 9 SEM micrographs of machined surfaces when cutting perpendicular to fibre direction from (a) test 14 - lowest MRR; (b) test 6-median MRR; and (c) test 4 -highest MRR
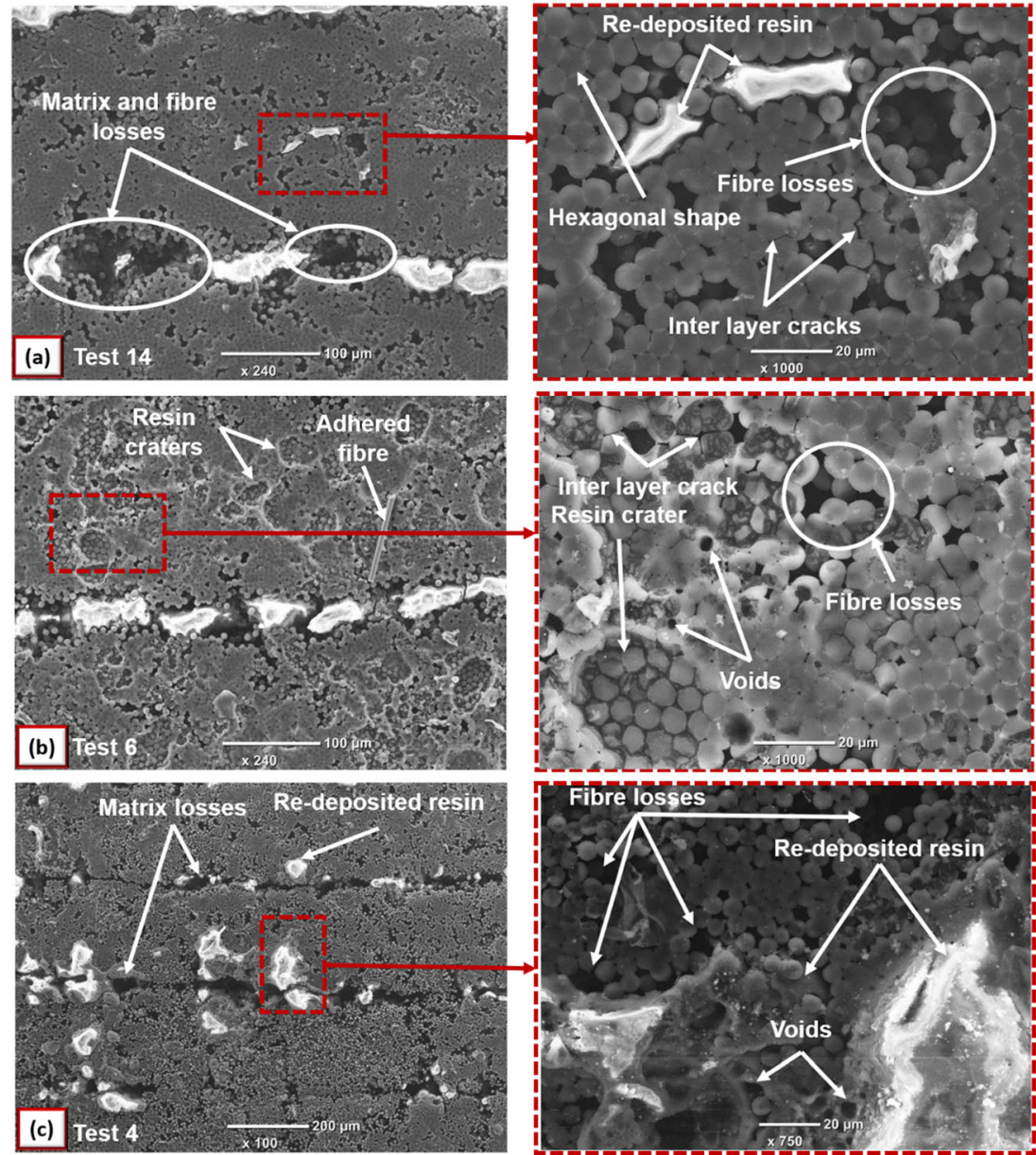

measured perpendicular to the feed, but with considerably less variability. The areal roughness was found to vary between 4.53 and $9.48 \mu \mathrm{m} \mathrm{Sa}$, with the highest level observed in test 9 corresponding to the fastest MRR.
Figure 14 details the average linear surface roughness $(\mathrm{Ra})$ measured parallel and perpendicular to feed direction together with the corresponding $3 \mathrm{D}$ areal roughness parameter $(\mathrm{Sa})$ for tests involving cutting perpendicular to fibre orientation. The
Fig. 10 Average kerf width when cutting parallel and perpendicular to fibres for each test

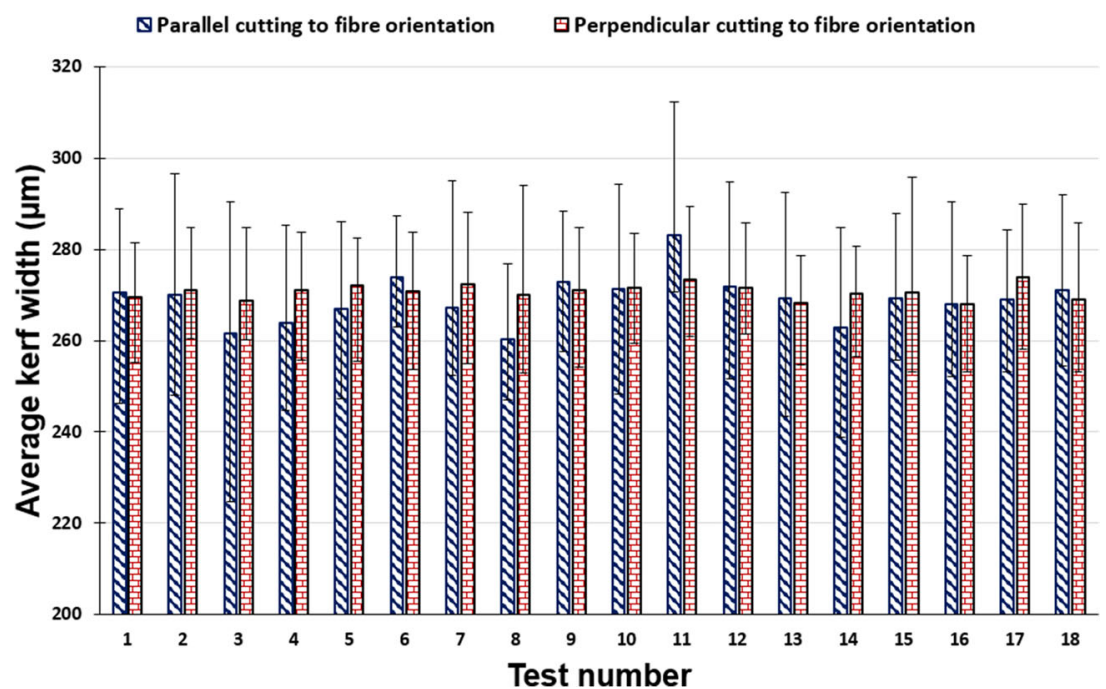


Table 7 Analysis of variance for average kerf width when cutting parallel to fibre direction

\begin{tabular}{|c|c|c|c|c|c|c|c|}
\hline Source & $\mathrm{DF}$ & Seq SS & Adj SS & Adj MS & $F$-value & $P$ value & PCR $(\%)$ \\
\hline $\mathrm{V}_{\mathrm{o}}$ & 1 & 46.037 & 46.037 & 46.037 & 1.65 & 0.228 & 9.87 \\
\hline IAL & 2 & 49.405 & 49.405 & 24.703 & 0.88 & 0.443 & 10.60 \\
\hline A & 2 & 9.931 & 9.931 & 4.966 & 0.18 & 0.840 & 2.13 \\
\hline B & 2 & 81.554 & 81.554 & 40.777 & 1.46 & 0.278 & 17.49 \\
\hline Error & 10 & 279.298 & 279.298 & 27.930 & & & 59.91 \\
\hline Total & 17 & 466.227 & & & & & 100.00 \\
\hline
\end{tabular}

Table 8 Analysis of variance for average kerf width when cutting perpendicular to fibre direction

\begin{tabular}{llllllr}
\hline Source & DF & Seq SS & Adj SS & Adj MS & $F$-value & $P$ value \\
\hline $\mathrm{V}_{\mathrm{o}}$ & 1 & 0.0071 & 0.0071 & 0.00714 & 0.00 & 0.961 \\
$\mathrm{IAL}$ & 2 & 0.6057 & 0.6057 & 0.30284 & 0.11 & 0.02 \\
$\mathrm{~A}$ & 2 & 9.2370 & 9.2370 & 4.61851 & 1.64 & 0.242 \\
$\mathrm{~B}$ & 2 & 8.2476 & 8.2476 & 4.12378 & 1.46 & 0.277 \\
Error & 10 & 28.1778 & 28.1778 & 2.81778 & & 1.31 \\
Total & 17 & 46.2752 & & & & 17.96 \\
\hline
\end{tabular}

roughness along the feed was generally lower than the transverse direction although the spread of the measurements was considerable, similar to the results when machining parallel to the fibres. Despite showing higher values compared to $\mathrm{Ra}$, the variation in Sa results was significantly lower with mean roughness ranging between 3.3 and $6.84 \mu \mathrm{m}$. In general, tests with higher MRR tended to exhibit increased surface roughness, most likely due to greater workpiece damage in terms of adhered/re-deposited resin and the formation of gaps between plies due to epoxy decomposition. The 3D topography plots of machined surfaces from tests exhibiting the highest MRR when cutting parallel (test 9) and perpendicular (test 4) to fibre direction are shown in Fig. 15. The presence of frayed fibres and adhered re-solidified resin were prevalent on the surface when machining parallel to the fibres, see Fig. 15a, whilst surfaces generated when cutting perpendicular to fibre direction exhibited adhered matrix material and cavities, particularly at the interface between plies; see Fig. 15b.

The statistical analysis of the surface roughness results was performed based on the areal roughness parameter (Sa) as this was a more representative measure of the machined surface topography compared to Ra. The main effects plot for surface roughness when machining parallel to the fibre direction shown in Fig. 16a indicates that
Fig. 11 Main effects plot for average kerf width when cutting parallel to fibre orientation

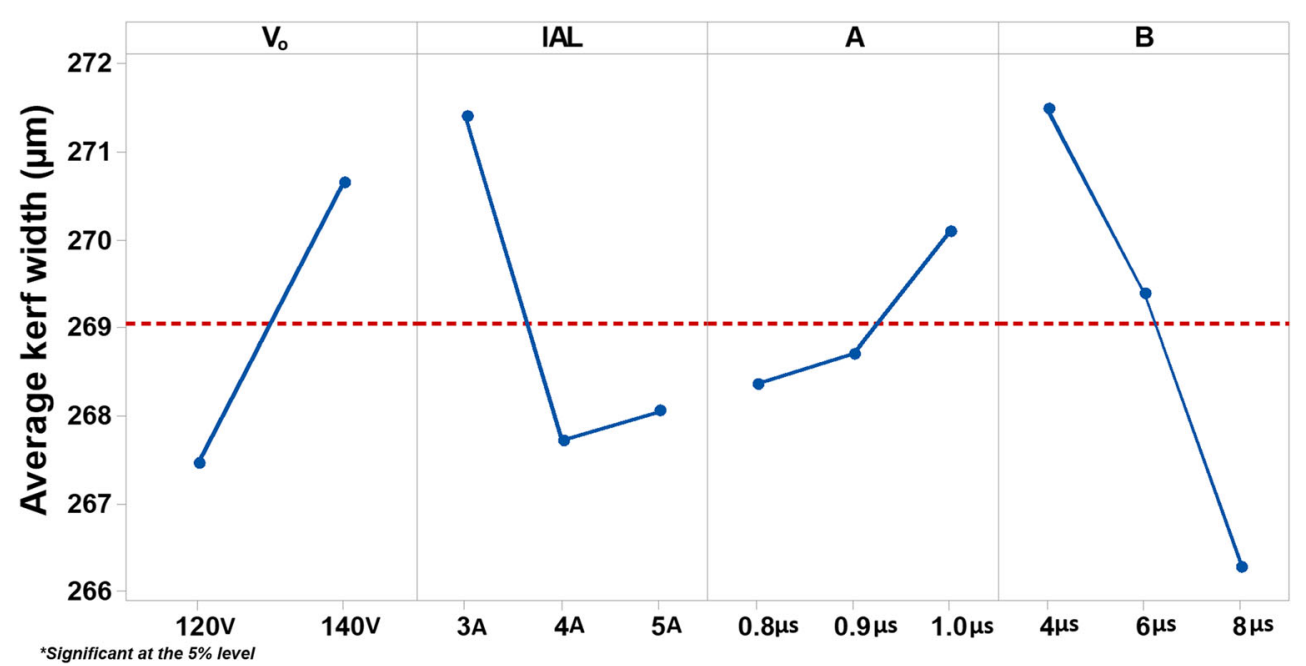


Fig. 12 Main effects plot for average kerf width when cutting perpendicular to fibre orientation

Fig. 13 Surface roughness parameters for each test when cutting parallel to fibre orientation

Fig. 14 Average surface roughness for each test when cutting perpendicular to fibre orientation
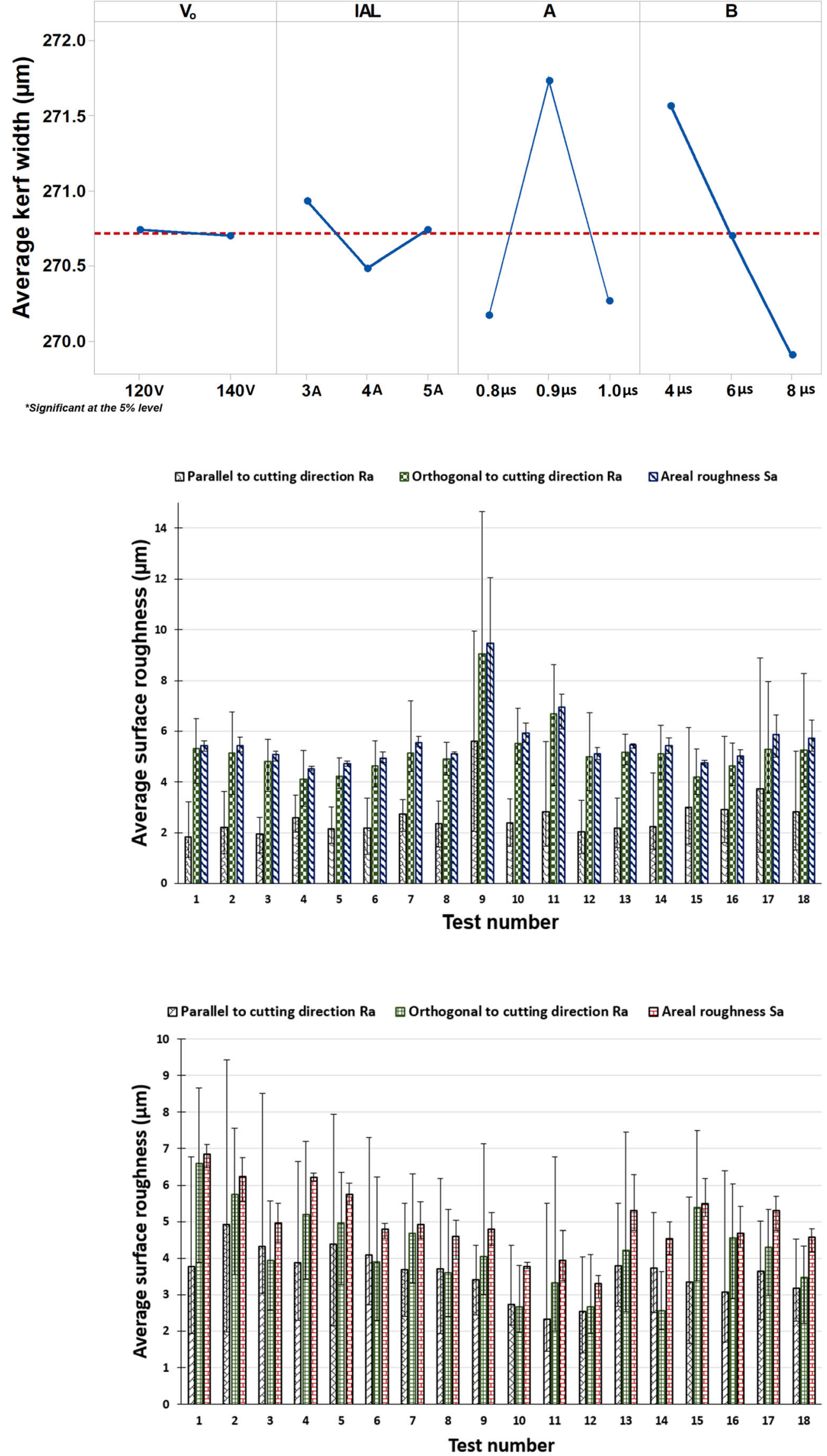
(a)

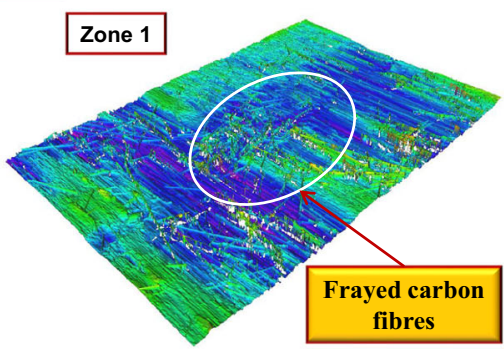

Test 9 - machined parallel to fibre
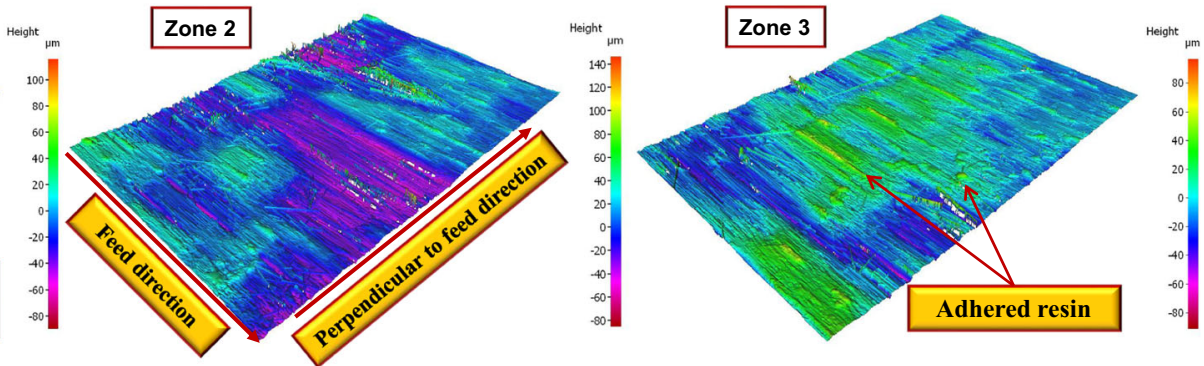

Test 4 - machined perpendicular to fibre
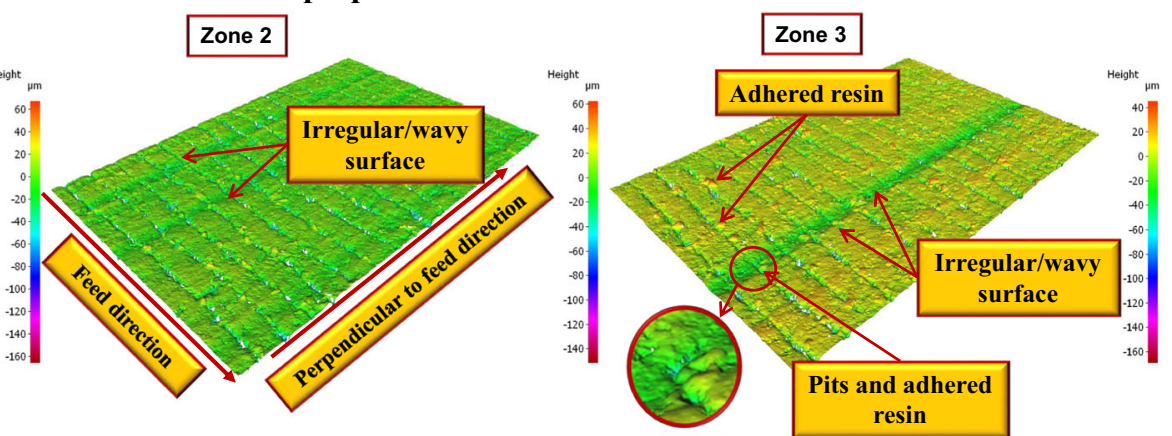

Fig. 15 3D surface topography plots of machined workpieces from tests exhibiting the highest MRR when cutting a parallel and $\mathbf{b}$ perpendicular to fibre direction

increasing pulse-on time whilst reducing pulse-off time resulted in higher mean surface roughness $(\mathrm{Sa})$ due to higher discharge energy and decreased flushing efficiency respectively. Increasing ignition current from 3 to $4 \mathrm{~A}$ initially lowered surface roughness probably due to lack of sufficient energy to remove material at low current $(3$ A) leaving irregular surfaces or uncut/frayed fibres, but a significant rise in roughness was subsequently apparent as current was increased to 5 A caused by greater discharge energy. The influence of gap voltage on mean surface roughness however appeared to be negligible. Corresponding analysis of variance (ANOVA) highlighted that none of the factors had a significant effect on workpiece surface roughness, with associated PCRs not exceeding of $20 \%$, as shown in Table 9. Conversely, open gap voltage was the sole significant factor affecting workpiece surface roughness (Sa) with a PCR of $\sim 27 \%$ when cutting perpendicular to the fibre direction; see Table 10 . The main effects plot in Fig. 16b showed that increasing voltage and pulse-off time led to lower workpiece surface roughness. This was probably due in part to the lower spark frequency and MRR at higher pulse-off time and voltage, respectively, resulting in a reduced number of craters on the machined surface. Higher pulse-on times were also found to reduce surface roughness as a result of increased short circuit discharges and greater fractured fibre debris contaminating the spark gap. The relatively high residual error of $62.36 \%$ and $38.94 \%$ recorded in the
ANOVA for surface roughness in Tables 9 and 10 respectively was likely due to other factors such as interactions not being considered, similar to that detailed previously for kerf width.

\subsection{Confirmation tests}

Based on the signal to noise $(\mathrm{S} / \mathrm{N})$ ratio calculations and main effects plots, the preferred levels of variable factors for achieving maximum MRR as well as minimum kerf width and areal surface roughness were selected for confirmation trials. Table 11 details the predicted/experimental mean and S/N ratio of the respective responses from the confirmation tests for cutting parallel and perpendicular to the fibre direction. The results revealed that the relative error for all responses were within 5\%, except for areal roughness when cutting parallel to the fibres, which was $\sim 10 \%$.

For cutting parallel to fibre orientation, the confirmation test parameters were equivalent to test 9 from the Taguchi array, with the machined surface condition similar to that shown in Fig. 8(c). The confirmation trial carried out for cutting perpendicular to the fibre orientation achieved a marginally higher material removal rate of $2.08 \mathrm{~mm}^{3} / \mathrm{min}$, compared to $1.94 \mathrm{~mm}^{3} / \mathrm{min}$ in test 4 ; however, evaluation of the corresponding machined surface revealed considerable damage including large cavities with voids, matrix loss caused by resin evaporation and eroded fibre ends. There was also significant 
Fig. 16 Main effects plot for surface roughness when cutting a parallel and $\mathbf{b}$ perpendicular to fibre orientation
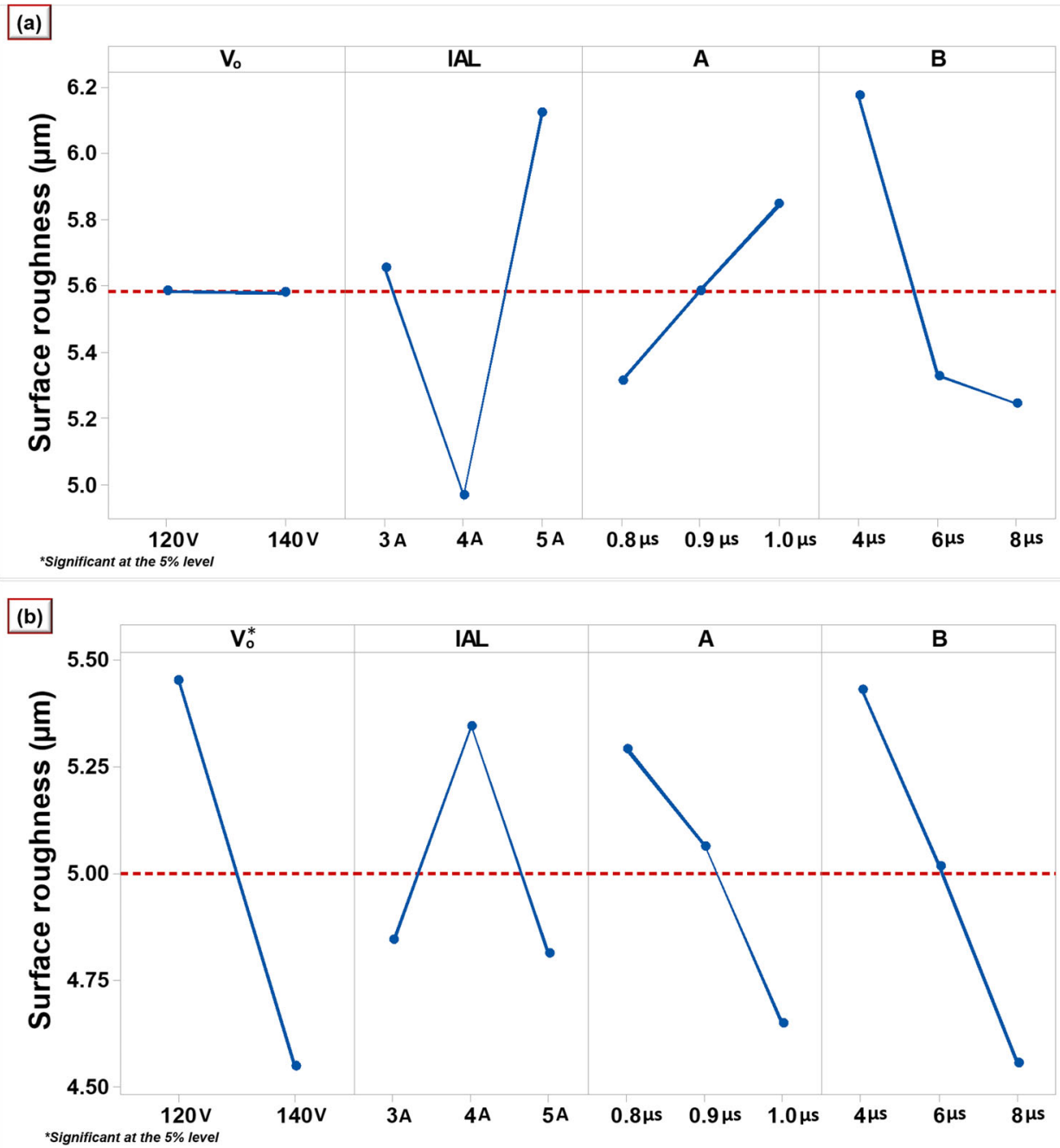

areas with re-solidified resin including cracks and voids over the surface; see Fig. 17.

\section{Conclusions}

The influence of cutting direction with respect to workpiece fibre orientation together with key operating parameters including open gap voltage, ignition current and pulse-on and pulse-off time was evaluated for WEDM of unidirectional CFRP laminates. Performance was assessed in terms of material removal rate, average kerf width and workpiece surface roughness.

- The highest MRR achieved when machining parallel to fibre direction was $2.41 \mathrm{~mm}^{3} / \mathrm{min}$, with both ignition

Table 9 Analysis of variance for surface roughness (Sa) when cutting parallel to fibre direction

\begin{tabular}{llllllc}
\hline Source & DF & Seq SS & Adj SS & Adj MS & $F$-value & $P$ value \\
\hline $\mathrm{V}_{\mathrm{o}}$ & 1 & 0.0000 & 0.0000 & 0.00004 & 0.00 & 0.996 \\
$\mathrm{IAL}$ & 2 & 4.0430 & 4.0430 & 2.02149 & 1.52 & 0.00 \\
$\mathrm{~A}$ & 2 & 0.8456 & 0.8456 & 0.42281 & 0.32 & $1 \%$ \\
$\mathrm{~B}$ & 2 & 3.1407 & 3.1407 & 1.57036 & 1.18 & 0.735 \\
Error & 10 & 13.3024 & 13.3024 & 1.33024 & & 0.347 \\
Total & 17 & 21.3318 & & & & 14.96 \\
\hline
\end{tabular}


Table 10 Analysis of variance for surface roughness (Sa) when cutting perpendicular to fibre direction

\begin{tabular}{lllllllr}
\hline Source & DF & Seq SS & Adj SS & Adj MS & $\begin{array}{l}F- \\
\text { value }\end{array}$ & $P$ value \\
\hline $\mathrm{V}_{\mathrm{o}}$ & 1 & 3.674 & 3.674 & 3.6745 & 6.93 & $0.025^{*}$ \\
$\mathrm{IAL}$ & 2 & 1.073 & 1.073 & 0.5364 & 1.01 & 0.398 \\
$\mathrm{~A}$ & 2 & 1.267 & 1.267 & 0.6335 & 1.19 & 0.343 & 7.87 \\
$\mathrm{~B}$ & 2 & 2.306 & 2.306 & 1.1528 & 2.17 & 0.165 & 16.92 \\
Error & 10 & 5.306 & 5.306 & 0.5306 & & 38.94 \\
Total & 17 & 13.626 & & & & 100.00 \\
\hline
\end{tabular}

*Significant at the $5 \%$ level

Table 11 Predicted and experimental results of confirmation tests

\begin{tabular}{|c|c|c|c|c|c|c|c|}
\hline \multirow[t]{2}{*}{ Cutting direction } & \multirow[t]{2}{*}{ Optimal levels } & \multirow[t]{2}{*}{ Response } & \multicolumn{2}{|l|}{ Mean } & \multicolumn{2}{|c|}{$\mathrm{S} / \mathrm{N}$ ratio $(\mathrm{dB})$} & \multirow[t]{2}{*}{ Error \% } \\
\hline & & & Pred. & Exp. & Pred. & Exp. & \\
\hline \multirow[t]{3}{*}{ Parallel } & $\mathrm{V}_{1} \mathrm{I}_{3} \mathrm{~A}_{3} \mathrm{~B}_{1}$ & MRR & 2.17 & 2.28 & 7.79 & 7.16 & 4.82 \\
\hline & $\mathrm{V}_{1} \mathrm{I}_{2} \mathrm{~A}_{1} \mathrm{~B}_{3}$ & Wa & 262.67 & 267.55 & -48.39 & -48.54 & 1.82 \\
\hline & $\mathrm{V}_{1} \mathrm{I}_{2} \mathrm{~A}_{1} \mathrm{~B}_{3}$ & $\mathrm{Sa}$ & 4.37 & 4.89 & -13.07 & -13.79 & 10.63 \\
\hline \multirow[t]{3}{*}{ Perpendicular } & $\mathrm{V}_{1} \mathrm{I}_{3} \mathrm{~A}_{1} \mathrm{~B}_{1}$ & MRR & 2.03 & 2.08 & 7.00 & 6.36 & 2.4 \\
\hline & $\mathrm{V}_{2} \mathrm{I}_{2} \mathrm{~A}_{1} \mathrm{~B}_{3}$ & Wa & 269.10 & 268.73 & -48.60 & -48.59 & $-0.14 *$ \\
\hline & $\mathrm{V}_{2} \mathrm{I}_{1} \mathrm{~A}_{3} \mathrm{~B}_{3}$ & $\mathrm{Sa}$ & 3.60 & 3.79 & -11.29 & -11.57 & 5.01 \\
\hline
\end{tabular}

*A negative error indicates that the experimental value is lower than predicted result

current and pulse-off time being statistically significant factors. No major damage however was observed on the kerf edges. The maximum MRR was marginally lower at $2.08 \mathrm{~mm}^{3} / \mathrm{min}$ when cutting perpendicular to the fibre orientation, which was likely due to the lower workpiece electrical conductivity. However, considerable delamination extending along the kerf edges was observed when cutting perpendicular to the fibres.
- Average kerf widths exhibited larger variation when cutting parallel to the fibres compared to tests performed perpendicular to the fibre direction. This was mainly attributed to the lower workpiece electrical conductivity when machining perpendicular to the fibre direction, in addition to the re-solidified resin layer on the machined surface acting as an insulator preventing the current/heat flow along the fibre axis

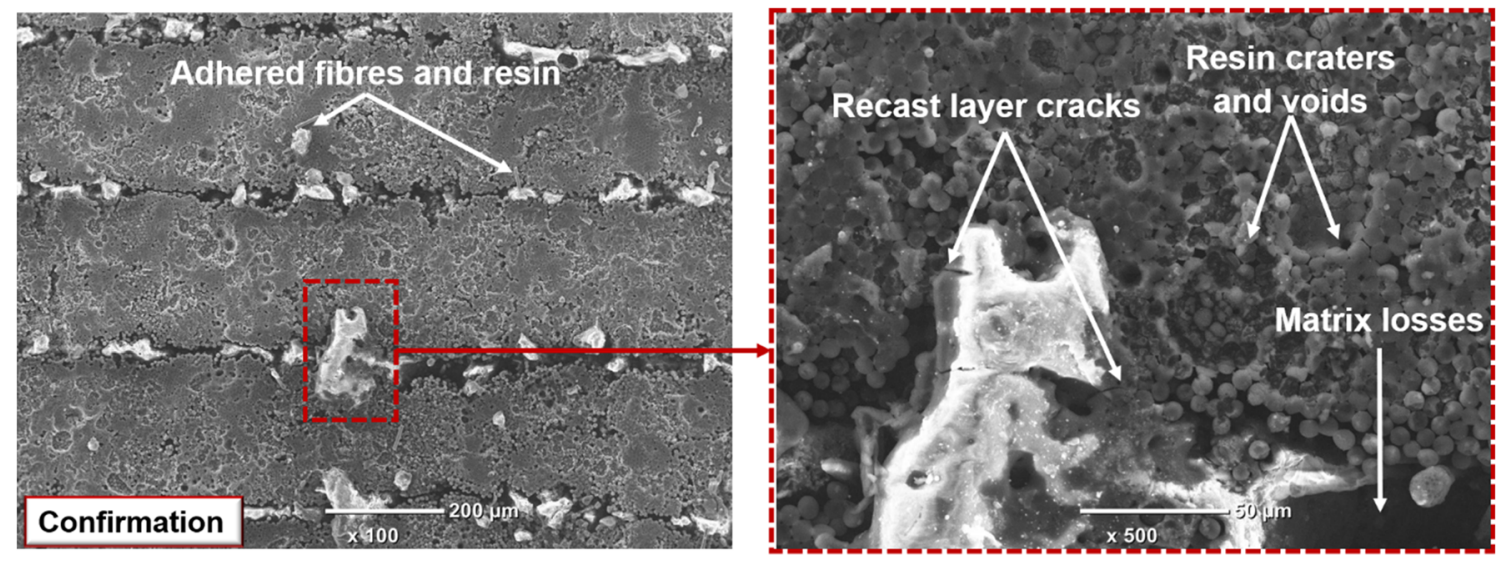

Fig. 17 SEM micrographs of machined surface from confirmation trial when cutting perpendicular to fibre orientation 
- The machined surface roughness was typically higher when cutting parallel to the fibre direction (4.53$9.48 \mu \mathrm{m} \mathrm{Sa}$ ) compared to when machining perpendicular to the fibres $(3.3-6.84 \mu \mathrm{m} \mathrm{Sa})$. This was due to the increased discharge energy when cutting parallel to the workpiece fibres, resulting in larger craters and surface damage.

- Machined surfaces were mainly characterised by resolidified resin adhering on the workpiece, loose/ fractured fibres, matrix loss/decomposition and swollen/ hexagonal-shaped ends of fibres due to high temperatures/ heat generated by the spark discharges.

Acknowledgements The authors would like to thank the Egyptian Cultural and Educational Bureau for funding a research studentship for the work.

Author contribution Ramy Abdallah: experimental investigation and analysis, methodology, writing - initial draft preparation

Sein Leung Soo: project conceptualisation and administration, supervision, writing - review and editing

Richard Hood: supervision, writing — review and editing

Data availability The manuscript has no associated data or the data will not be deposited.

\section{Declarations}

Ethics approval and consent to participate Not applicable

Consent for publication Not applicable

Conflict of interest The authors declare no competing interests.

Code availability Not applicable

Open Access This article is licensed under a Creative Commons Attribution 4.0 International License, which permits use, sharing, adaptation, distribution and reproduction in any medium or format, as long as you give appropriate credit to the original author(s) and the source, provide a link to the Creative Commons licence, and indicate if changes were made. The images or other third party material in this article are included in the article's Creative Commons licence, unless indicated otherwise in a credit line to the material. If material is not included in the article's Creative Commons licence and your intended use is not permitted by statutory regulation or exceeds the permitted use, you will need to obtain permission directly from the copyright holder. To view a copy of this licence, visit http://creativecommons.org/licenses/by/4.0/.

\section{References}

1. Li Z, Meng Z (2016) A review of the radio frequency nondestructive testing for carbon fibre composites. Meas Sci Rev 16(2):68-76. https://doi.org/10.1515/msr-2016-0010

2. Mohee FM, Al-Mayah A, Plumtree A (2016) Anchors for CFRP plates: state-of- the-art review and future potential. Compos Part B-
Eng 90:432-442. https://doi.org/10.1016/j.compositesb.2016.01. 011

3. Qiu X, Li P, Ni Q, Chen A, Ouyang P, Li C, Ko TJ (2018) Influence of machining parameters and tool structure on cutting force and hole wall damage in drilling CFRP with stepped drills. Int J Adv Manuf Technol 87:857-865. https://doi.org/10.1007/s00170-0181981-2

4. Konig W, Wulf C, Gra $\beta$ P, Willerscheid H (1985) Machining of fibre reinforced plastics. CIRP Ann Manuf Technol 34(2):537-548. https://doi.org/10.1016/S0007-8506(07)60186-3

5. Akematsu Y, Kageyama K, Murayama H (2016) Basic characteristics of electrical discharge on CFRP by using thermal camera. Procedia CIRP 42:197-200. https://doi.org/10.1016/j.procir.2016. 02.270

6. Sekaran SC, Yap HJ, Liew KE, Kamaruzzaman H, Tan CH, Rajab RS (2019) Haptic-based virtual reality system to enhance actual aerospace composite panel drilling training. In: Jawaid M, Thariq M, Saba N (eds.) Structural health monitoring of biocomposites, fibre-reinforced composites and hybrid composites, $1^{\text {st }}$ edn. Woodhead Publishing, pp 113-128

7. El-Hofy MH, Soo SL, Aspinwall DK, Sim WM, Pearson D, M'Saoubi R, Harden P (2017) Tool temperature in slotting of CFRP composites. Procedia Manufacturing 10:371-381. https:// doi.org/10.1016/j.promfg.2017.07.007

8. Kumar D, Singh KK (2015) An approach towards damage free machining of CFRP and GFRP composite material: a review. Adv Compos Mater 24:49-63. https://doi.org/10.1080/09243046. 2014.928966

9. Kim D, Beal A, Kwon P (2016) Effect of tool wear on hole quality in drilling of carbon fiber reinforced plastic-titanium alloy stacks using tungsten carbide and polycrystalline diamond tools. J Manuf Sci Eng 138(3):031006(1-11). https://doi.org/10.1115/1.4031052

10. Phadnis VA, Makhdum F, Roy A, Silberschmidt VV (2012) Experimental and numerical investigations in conventional and ultrasonically assisted drilling of CFRP laminate. Procedia CIRP 1: 455-459. https://doi.org/10.1016/j.procir.2012.04.081

11. Sheikh-Ahmad JY, Shinde SR (2016) Machinability of carbon/ epoxy composites by electrical discharge machining. Int J Mach Mach Mater 18(1-2):3-17. https://doi.org/10.1504/IJMMM.2016. 075452

12. Al-Wandi S, Ding S, Mo J (2017) An approach to evaluate delamination factor when drilling carbon fiber-reinforced plastics using different drill geometries: experiment and finite element study. Int J Adv Manuf Technol 93(9-12):4043-4061. https://doi.org/10.1007/ s00170-017-0880-2

13. Geier N, Szalay T, Takács M (2019) Analysis of thrust force and characteristics of uncut fibres at non-conventional oriented drilling of unidirectional carbon fibre-reinforced plastic (UD-CFRP) composite laminates. Int J Adv Manuf Technol 100(9-12):3139-3154. https://doi.org/10.1007/s00170-018-2895-8

14. Jia Z-Y, Chen C, Wang F-J, Zhang C, Wang Q (2020) Analytical model for delamination of CFRP during drilling of CFRP/metal stacks. Int J Adv Manuf Technol 106(11):5099-5109. https://doi. org/10.1007/s00170-020-05029-y

15. Sun L, Gao H, Wang B, Bao Y, Wang M, Ma S (2020) Mechanism of reduction of damage during helical milling of titanium/CFRP/ aluminium stacks. Int J Adv Manuf Technol 107(11-12):47414753. https://doi.org/10.1007/s00170-020-05177-1

16. Dhanawade A, Kumar S (2017) Experimental study of delamination and kerf geometry of carbon epoxy composite machined by abrasive water jet. J Compos Mater 51(24):3373-3390. https://doi. org/10.1177/0021998316688950

17. Wang H, Ning F, Hu Y, Li Y, Wang X, Cong W (2018) Edge trimming of carbon fiber-reinforced plastic composites using rotary ultrasonic machining: effects of tool orientations. Int J Adv Manuf 
Technol 98(5-8):1641-1653. https://doi.org/10.1007/s00170-0182355-5

18. Hu J, Zhu D (2018) Investigation of carbon fiber reinforced plastics machining using $355 \mathrm{~nm}$ picosecond pulsed laser. Appl Compos Mater 25(3):589-600. https://doi.org/10.1007/s10443-017-9637-1

19. Habib S, Okada A (2016) Influence of electrical discharge machining parameters on cutting parameters of carbon fiber-reinforced plastic. Mach Sci Technol 20(1):99-114. https://doi.org/10.1080/ 10910344.2015.1133914

20. Phapale K, Singh R, Patil S, Singh RKP (2016) Delamination characterization and comparative assessment of delamination control techniques in abrasive water jet drilling of CFRP. Procedia Manufacturing 5:521-535. https://doi.org/10.1016/j.promfg.2016. 08.043

21. Sheikh-Ahmad JY (2016) Hole quality and damage in drilling carbon/epoxy composites by electrical discharge machining. Mater Manuf Processes 31(7):941-950. https://doi.org/10.1080/ 10426914.2015.1048368

22. Yue X, Yang X, Tian J, He Z, Fan Y (2018) Thermal, mechanical and chemical material removal mechanism of carbon fiber reinforced polymers in electrical discharge machining. Int J Mach Tools Manuf 133:4-17. https://doi.org/10.1016/j.ijmachtools. 2018.05.004

23. Islam MM, Li CP, Won SJ, Ko TJ (2017) A deburring strategy in drilled hole of CFRP composites using EDM process. J Alloys Compd 703:477-485. https://doi.org/10.1016/j.jallcom.2017.02. 001

24. Islam MM, Li CP, Ko TJ (2017) Dry electrical discharge machining for deburring drilled holes in CFRP composite. Int J Precis Eng Manuf - Green Technol 4(2):149-154. https://doi.org/10.1007/ s40684-017-0018-x

25. Kurniawan R, Kumaran ST, Prabu VA, Zhen Y, Park KM, Kwak YI, Islam MM, Ko TJ (2017) Measurement of burr removal rate and analysis of machining parameters in ultrasonic assisted dry EDM (US-EDM) for deburring drilled holes in CFRP composite. Measurement 110:98-115. https://doi.org/10.1016/j.measurement. 2017.06.008

26. Kumar R, Agrawal PK, Singh I (2018) Fabrication of micro holes in CFRP laminates using EDM. J Manuf Processes 31:859-866. https://doi.org/10.1016/j.jmapro.2018.01.011
27. Lau WS, Lee WB (1991) A comparison between EDM wire cut and laser cutting of carbon fiber composite materials. Mater Manuf Processes 6:331-342. https://doi.org/10.1080/ 10426919108934760

28. Abdallah R, Soo SL, Hood R (2018) A feasibility study on wire electrical discharge machining of carbon fibre reinforced plastic composites. Procedia CIRP 77:195-198. https://doi.org/10.1016/j. procir.2018.08.284

29. Dutta H, Debnath K, Sarma DK (2020) A Study of wire electrical discharge machining of carbon fibre reinforced plastic. In: Shunmugam M, Kanthababu M (eds) Advances in Unconventional Machining and Composites. Lecture Notes on Multidisciplinary Industrial Engineering. Springer, Singapore. https://doi.org/10.1007/978-981-32-9471-4_36

30. Wu C, Cao S, Zhao YJ, Qi H, Liu X, Liu G, Guo J, Li HN (2021) Preheating assisted wire EDM of semi-conductive CFRPs: principle and anisotropy. J Mater Process Technol 288:116915. https:// doi.org/10.1016/j.jmatprotec.2020.116915

31. Ji R, Liu Y, Diao R, Xu C, Li X, Cai B, Zhang Y (2014) Influence of electrical resistivity and machining parameters on electrical discharge machining performance of engineering ceramics. PLoS One, 9(11), e110775 (1-9). https://doi.org/10.1371/journal.pone. 0110775

32. Habib S, Okada A, Ichii S (2013) Effect of cutting direction on machining of carbon fibre reinforced plastic by electrical discharge machining process. Int J Mach Mach Mater 13(4):414-427. https:// doi.org/10.1504/IJMMM.2013.054272

33. Davim JP, Reis P (2005) Damage and dimensional precision on milling carbon fiber-reinforced plastics using design experiments. J Mater Process Technol 160(2):160-167. https://doi.org/10.1016/j. jmatprotec.2004.06.003

34. Lin Y-C, Chen Y-F, Wang D-A, Lee H-S (2009) Optimization of machining parameters in magnetic force assisted EDM based on Taguchi method. J Mater Process Technol 209(7):3374-3383. https://doi.org/10.1016/j.jmatprotec.2008.07.052

Publisher's note Springer Nature remains neutral with regard to jurisdictional claims in published maps and institutional affiliations. 